\title{
Article
}

\section{Electrochemical single-molecule transistors with optimized gate coupling}

Henrry M. Osorio, Samantha Catarelli, Pilar Cea, Josef B. G. Gluyas, Frantisek Hartl, Simon J. Higgins, Edmund Leary, Paul J. Low, Santiago Martin, Richard J. Nichols, Joanne Tory, Jens Ulstrup, Andrea Vezzoli, Qiang Zeng, and David Costa Milan

J. Am. Chem. Soc., Just Accepted Manuscript • DOI: 10.1021/jacs.5b08431 • Publication Date (Web): 21 Oct 2015

Downloaded from http://pubs.acs.org on October 29, 2015

\section{Just Accepted}

"Just Accepted" manuscripts have been peer-reviewed and accepted for publication. They are posted online prior to technical editing, formatting for publication and author proofing. The American Chemical Society provides "Just Accepted" as a free service to the research community to expedite the dissemination of scientific material as soon as possible after acceptance. "Just Accepted" manuscripts appear in full in PDF format accompanied by an HTML abstract. "Just Accepted" manuscripts have been fully peer reviewed, but should not be considered the official version of record. They are accessible to all readers and citable by the Digital Object Identifier (DOI@). "Just Accepted" is an optional service offered to authors. Therefore, the "Just Accepted" Web site may not include all articles that will be published in the journal. After a manuscript is technically edited and formatted, it will be removed from the "Just Accepted" Web site and published as an ASAP article. Note that technical editing may introduce minor changes to the manuscript text and/or graphics which could affect content, and all legal disclaimers and ethical guidelines that apply to the journal pertain. ACS cannot be held responsible for errors or consequences arising from the use of information contained in these "Just Accepted" manuscripts. 
Electrochemical single-molecule transistors with optimized gate coupling

Henrry M. Osorio, ${ }^{(a)}$ Samantha Catarelli, ${ }^{(b)}$ Pilar Cea, ${ }^{(a, c)}$ Josef B. G. Gluyas, ${ }^{(d)}$ František Hartl, ${ }^{(e)}$ Simon J. Higgins, ${ }^{(b)}$ Edmund Leary, ${ }^{(b)}$ Paul J. Low, ${ }^{(d)}$ Santiago Martín, ${ }^{(a, f)}$ Richard J. Nichols, ${ }^{(b)}{ }^{*}$ Joanne Tory, ${ }^{(e)}$ Jens Ulstrup, ${ }^{\left({ }^{(}\right)}$Andrea Vezzoli, ${ }^{(b)}$ David C. Milan ${ }^{(b)}$ and Qiang Zeng. $^{(e)}$

(a) Departamento de Química Física, Facultad de Ciencias, Universidad de Zaragoza, 50009, Spain.

(b) Department of Chemistry, University of Liverpool, Crown Street, Liverpool, L69 7ZD, United Kingdom.

(c) Instituto de Nanociencia de Aragón (INA) and Laboratorio de microscopias avanzadas (LMA), edificio i+d Campus Rio Ebro, Universidad de Zaragoza, C/Mariano Esquillor, s/n, 50018 Zaragoza, Spain.

(d) School of Chemistry and Biochemistry, University of Western Australia, 35 Stirling Highway, Crawley 6009, Australia

(e) Department of Chemistry, University of Reading, Whiteknights, Reading, RG6 6AD, UK

(f) Instituto de Ciencias de Materiales de Aragón (ICMA), Universidad de Zaragoza-CSIC, 50009 Zaragoza, Spain.

(g) Department of Chemistry and NanoDTU, Technical University of Denmark, DK2800 Kgs. Lyngby, Denmark.

*Corresponding author e-mail address: nichols@liv.ac.uk

\section{ABSTRACT}

Electrochemical gating at the single molecule level of viologen molecular bridges in ionic liquids is examined. Contrary to previous data recorded in aqueous electrolytes, a clear and sharp peak in the single molecule conductance versus electrochemical potential data is obtained in ionic liquids. These data are rationalized in terms of a two-step electrochemical 
model for charge transport across the redox bridge. In this model the gate coupling in the ionic liquid is found to be fully effective with a modeled gate coupling parameter, $\xi$, of unity. This compares to a much lower gate coupling parameter of 0.2 for the equivalent aqueous gating system. This study shows that ionic liquids are far more effective media for gating the conductance of single molecules than either solid-state three-terminal platforms created using nanolithography, or aqueous media.

Keywords: spectro-electrochemistry, electrochemical double layer, STM, molecular electronics, charge transfer, viologens, ionic liquids.

\section{$\underline{\text { Introduction }}$}

Molecular switching, for instance between low and high conductance states, has been a theme of ongoing interest in molecular electronics and it has been shown in recent years that this can be achieved even down to the single molecule level. ${ }^{1}$ Molecular analogues of field effect transistors have been achieved, in which the conductance state of a molecular junction can be electrostatically modulated by a third (gate) terminal. In solid-state devices this has to be achieved by bringing the gate terminal into close proximity to the molecule that is wired between two contacting electrodes (source and drain). Since the separation of the source and drain electrodes will be of molecular dimensions, it is a considerable challenge to bring the gate electrode reliably into close enough proximity to gate the molecular junction electrostatically. Nevertheless, capacitive coupling of the molecular junction to the gate electrode has been achieved in solid-state platforms either using nanolithographically fabricated electrodes, or mechanically controlled break junctions constructed on a substrate bearing an electrostatic 'back gate' electrode. If the gate is perfectly electrostatically coupled to the junction, then frontier HOMO and LUMO molecular orbitals of the bridge would shift in unison with the applied gate voltage, to give a gate coupling parameter, here called $\xi$, of 1 (i.e. a $0.1 \mathrm{~V}$ shift of the gate voltage produces a $0.1 \mathrm{eV}$ shift in the molecular orbital energy). Although relatively large coupling parameters have been achieved for individual devices 
(e.g. $\sim 0.2),{ }^{2}$ the nanofabrication processes do not generally lend themselves to precise and reproducible placement of the gate electrode, and $\xi$ is typically much lower than this, and moreover exhibits significant variation from device to device. An alternative approach is to use liquid gates, with control of the electrochemical double layer.

"Electrolyte gating" relies on the formation of electrochemical double layers along the source-drain channel. Since electrochemical double layers can have nanometer thicknesses separating electronic surface charge and ions in solution, even at modest electrolyte concentrations, they provide both an effective and a highly reproducible gating platform. Moreover, the gate voltage is readily controlled through variation of the electrochemical potential. Electrolyte gating has been applied to a wide variety of bulk and nanostructured materials including nanocrystalline thin films, ${ }^{5}$ carbon nanotubes, ${ }^{3,4}$ and solid-state semiconductor devices in which the source-drain channel is a solid semiconductor or even a superconductor. ${ }^{6,7}$ Such devices are typically referred to as electrochemical double layer transistors (EDLTs). In 1984 White et al. reported on the fabrication of a polypyrrole derivatized microelectrode array that operated as a transistor through electrochemical control of the oxidation of the bulk conducting polymer film by a gating electrode. ${ }^{8}$ More recently, this electrochemical gating concept has been extended to the single molecular bridge level, in which the electrochemical potentials and resultant double layers tune molecular orbital energy levels. In the case of redox active molecular wires, this can be used to switch the molecule between accessible redox states. A schematic illustration of electrolyte gating of a single-molecule bridge is shown in Figure 1. The single molecule is tethered between the STM tip and substrate surface, which can be viewed as the drain and source electrodes respectively. The counter and reference electrode combination provides the gate electrode in this 4-electrode bipotentiostat setup, with independent electrochemical potential control of the substrate (working electrode 1, or "source") and the STM tip (working electrode 2, or "drain"). The potential difference between these two electrodes is the bias 
voltage applied to the molecular junction. Figure 1B illustrates that the redox group is gated by the close proximity of electrolyte ions

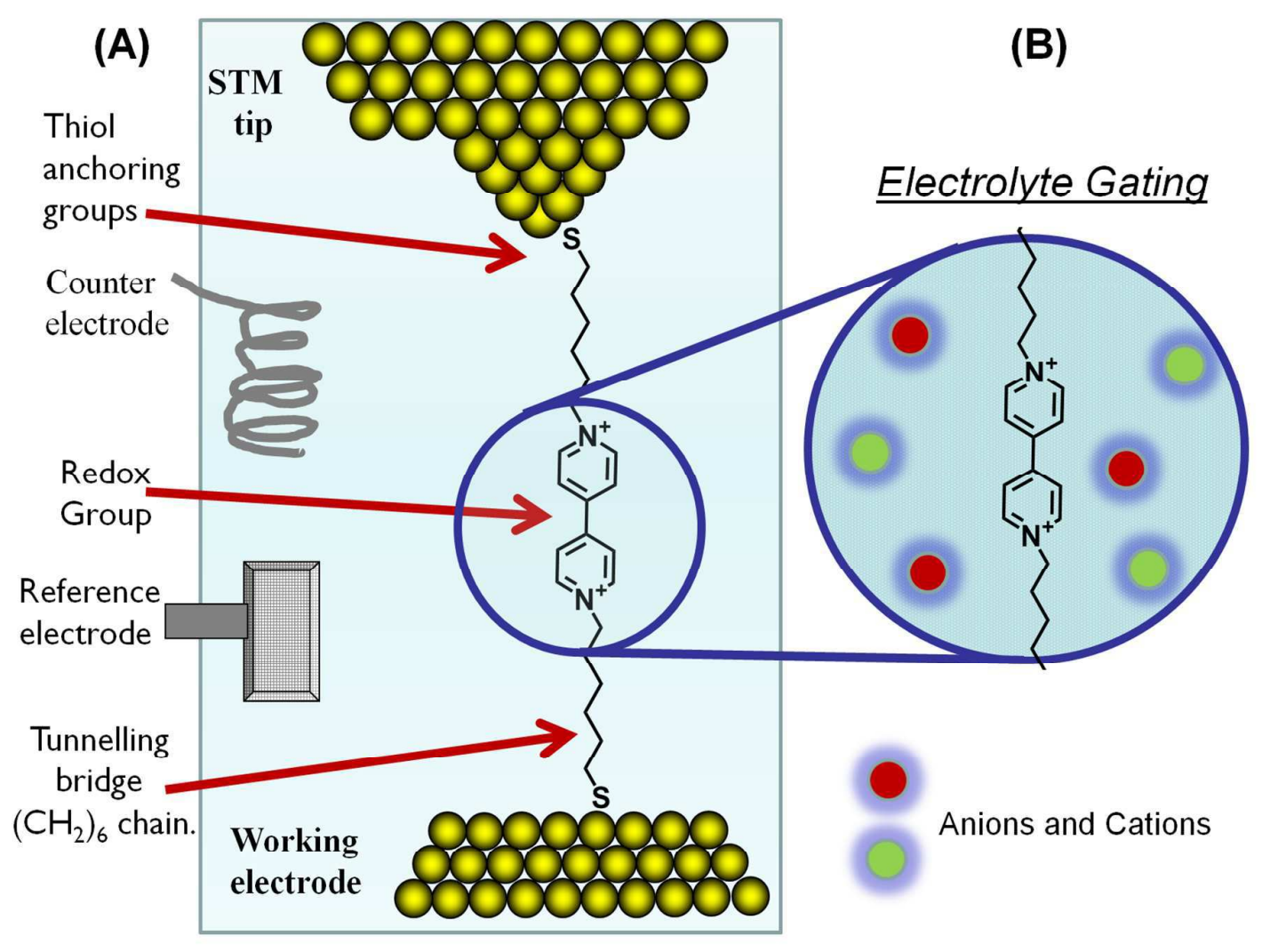

Figure 1: (A) Electrochemical single molecule gating using an electrochemical STM with bipotentiostat control of the electrochemical potential of the substrate and STM tip. The single molecule bridge shown here $\left(1^{2+}\right.$, see below) is derived from $1,1^{\prime}$-bis(6(acetylthio)hexyl)-4,4'-bipyridinium hexafluorophosphate. (B) Illustrates the close proximity of the electrolyte ions which are "gating" the redox group (the electrolyte gating concept).

There is now a growing number of examples of electrochemical gating of single molecules, using the single-molecule electrochemical transistor-like configuration where the molecular bridge is tethered between substrate and STM tip, both of which are typically made of gold. ${ }^{9-}$

${ }^{33}$ Viologen molecular wires were the first electrochemical redox system studied in this single-molecule junction configuration, with the molecule anchored to the source and drain 
electrodes through chemisorbed thiol contacting groups. ${ }^{10}$ This redox bridge system (the $\mathrm{V}^{2+} / \mathrm{V}^{+}$. redox system, with $\mathrm{V}=$ viologen) has continued to be of interest due to its highly reversible electrochemical reduction processes. ${ }^{11-13}$ Other examples of such "wired" singlemolecule electrochemical junctions include molecular wires containing pyrrolotetrathiafulvalene (pTTF) ${ }^{14,15}$ oligoanilines, ${ }^{16-18}$ oligothiophenes, ${ }^{19}$ unsubstituted and substituted oligo(phenylene ethynylenes) (OPEs), ${ }^{20-22}$ ferrocene,${ }^{23}$ anthraquinone,${ }^{24-26}$ perylene tetracarboxylic bisimides (PBI), ${ }^{27-31}$ carotenoids ${ }^{32}$ and benzodifuran. ${ }^{33}$ More recently, the electrolyte gating of non-redox active molecules has also been examined. ${ }^{34-36}$ Electrolyte gating where the redox active molecule is attached to the substrate but not the STM tip, or occasionally vice versa ${ }^{37-47}$ has also been demonstrated. In this configuration, electron tunneling through the adsorbed molecule as a function of electrochemical potential with the STM tip located above the adsorbed layer is monitored. ${ }^{37}$ This can be referred to as an electrochemical scanning tunneling spectroscopy configuration, and systems thus studied include, for example, metal complexes, $, 37,40,41,43,44$ metalloproteins, ${ }^{48-50}$ DNA, ${ }^{51} 52$ and viologens $^{13,46}$. Albrecht et al. pioneered electrochemical scanning tunneling spectroscopy experiments conducted in ionic liquid environments. ${ }^{53}$ There have also been studies of electrolyte gating in large area planar molecular junctions, ${ }^{54}$ as well as devices featuring single nanoparticles ${ }^{55}$ or fabricated nanoelectrode gaps. ${ }^{56,57}$

A comparison of the electrochemical gate voltage behavior reported in the single molecule studies mentioned above clearly indicates that the resulting gating response is highly variable. In some cases, in a plot of single-molecule conductance against applied electrochemical potential a peak is seen as the voltage is adjusted through the reversible potential for the redox switching. ${ }^{14,15,28,29,33,58,59}$ In other cases, no defined peak in the molecular conductance versus electrochemical potential is observed, but rather a monotonically rising conductance spanning many hundreds of millivolts; an early example of this latter behavior is the electrochemical gating of the conductance of viologen molecular wires in aqueous solution. ${ }^{10,13}$ In this case the conductance gradually rises as the 
electrochemical potential is taken from positive values where the molecule is in its oxidized (bipyridinium) state, to potentials negative of its first reduction; ${ }^{10-13}$ the term "soft gating" was coined to refer to this phenomenon. ${ }^{12}$ Similar broad conductance rise or broad conductance gating peaks feature in other electrochemical single-molecule conductance switching systems, such as those based on perylene bisimides, ${ }^{28,29,31,58}$ benzodifuran, ${ }^{33}$ anthraquinone-based norbornylogous bridges ${ }^{24} 25$ and metalloproteins. ${ }^{59} 60$ In this present study we examine electrochemical conductance gating of viologen-based single-molecule wire systems in ionic liquids and compare the response with data from aqueous media. The data recorded in ionic liquid reported here fit within the two-step (hopping) mechanism introduced by Kuznetsov and Ulstrup with a high gating coupling parameter of $\xi=1$. We refer here to such effective gating with a high gate coupling parameter as "hard gating". When the same model is applied to the data from similar studies of $1^{2+}$ in aqueous solution, a much lower gate coupling parameter of $\xi=0.2$ is obtained, which accounts for the broad rise in conductance with electrochemical potential. ${ }^{10,12,13}$ This difference in gating behavior between the two electrolytes arises from the gating provided by the double layers, which are expected to be very different in ionic liquids, which represent "highly concentrated and dense" 61 electrolyte media when compared with dilute aqueous electrolytes (the electrolytic properties of ionic liquids have been reviewed elsewhere ${ }^{61}$ ). UV/visible and IR spectroelectrochemical experiments in both aqueous and ionic liquid electrolytes show that the electronic structure of the reduced viologen is not changed by the ionic liquid electrolyte. The present study shows that ionic liquid electrochemical gating of single-molecule conductance is far more effective than gating that is generally achieved either in solid-state three-terminal platforms created using nanolithography or gating with aqueous double layers.

\section{- RESULTS}

The viologen based molecular wires used in this study (Chart 1) contained either classical thiol contacting groups $\left(1^{2+}\right)$, or the more esoteric trimethylsilylethynyl contacting groups 
$\left(2^{2+}\right)$. The acetyl-protected precursor $3 \cdot\left[\mathrm{PF}_{6}\right]_{2}$ was synthesized by the route shown in Scheme S1 (Supporting Information) and is an adaptation of the synthesis of bromide salts of $3^{2+}$ described elsewhere. ${ }^{62}$ Monolayers of $\mathbf{1}^{2+}$ form in situ upon exposure of gold substrates to solutions of the acetyl protected precursor $3 \cdot\left[\mathrm{PF}_{6}\right]_{2}$ (see Methods) for STM investigations. ${ }^{14}$ Compound $2^{2+}$ was synthesized as the bis tetrafluoroborate salt (Scheme 1 ). Sonogashira cross-coupling ${ }^{63-65}$ of ethynyltrimethylsilane (7) with 4-iodobenzyl alcohol (8), gave 4-(trimethylsilyl)ethynyl-benzyl alcohol (9). Bromination of compound 9 with $\mathrm{PPh}_{3}{ }^{\bullet} \mathrm{Br}_{2}{ }^{66}$ gave 4-(trimethylsilyl)ethynyl-benzyl bromide (10). The target viologen $\left(2^{2+}\right)$ was formed by condensation of 4,4'-bipyridine with 10 under reflux in acetonitrile and isolated following exchange of the bromide counter ions with ammonium tetrafluoroborate.
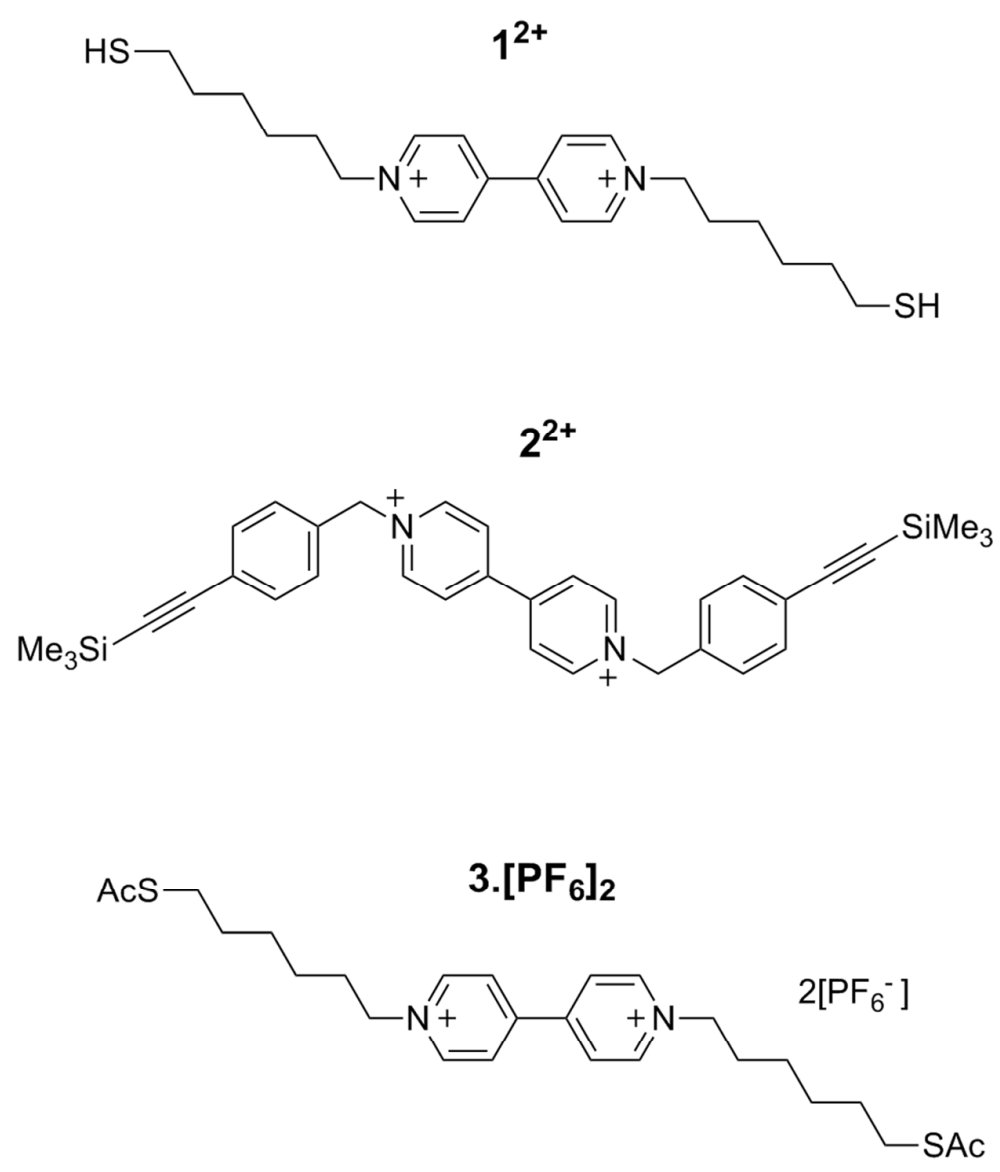
Chart 1: The viologen based molecular wires $\left(\mathbf{1}^{2+}\right.$ and $\left.\mathbf{2}^{2+}\right)$ used in the STM studies described within. Under the experimental conditions used the counter ions are determined by the electrolytic medium. $3 \cdot\left[\mathrm{PF}_{6}\right]_{2}$ is the acetyl protected precursor of $\mathbf{1}^{2+}$ with $\mathrm{PF}_{6}^{-}$ counter-ions.

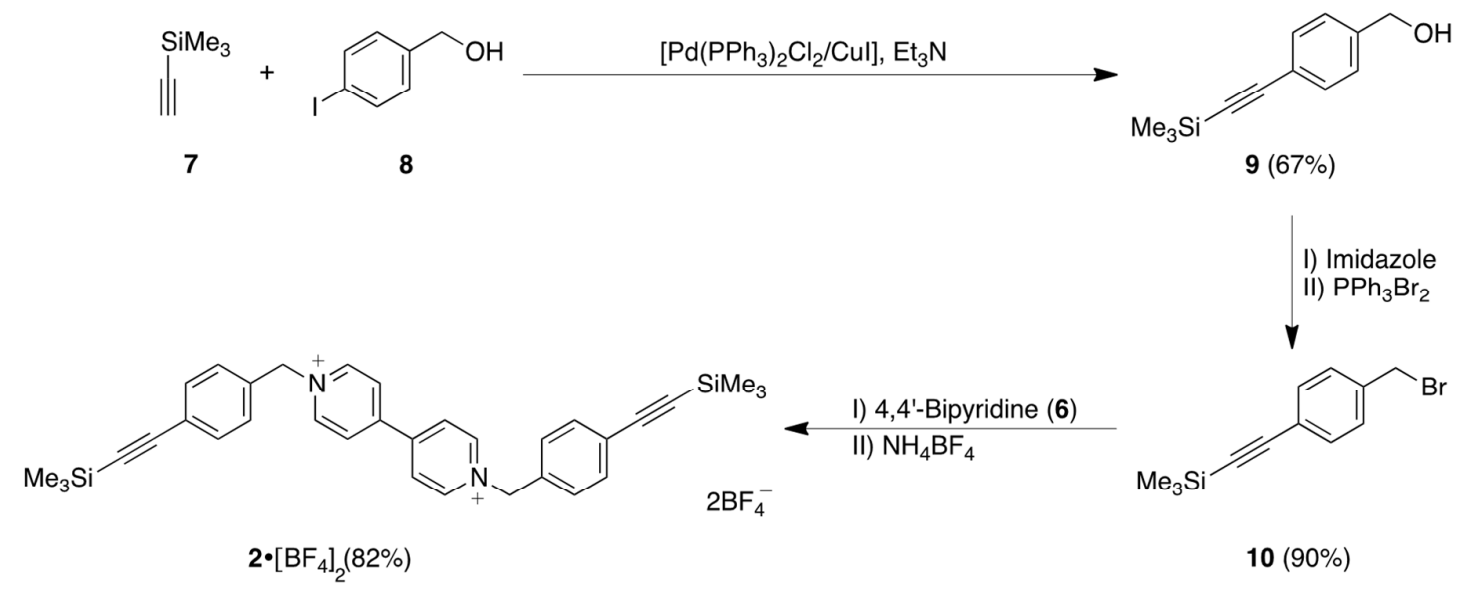

Scheme 1. Synthesis of $2 \cdot\left[\mathrm{BF}_{4}\right]_{2}$, yields are given in parentheses.

Cyclic voltammetry of the initial electrochemical reduction of $3 \cdot\left[\mathrm{PF}_{6}\right]_{2}$, the thioacetate protected form of $\mathbf{1}^{\mathbf{2 +}}$ in the ionic liquid 1-butyl-3-methylimidazolium triflate (BMIM-OTf) to its radical cation is shown in Figure 2. The redox wave centered at $0 \mathrm{~V}$ arises from ferrocene (Fc) added to the electrolyte for voltammetric calibration. ${ }^{67}$ The peak-to-peak separation for the viologen $\left(3^{2+} \leftrightarrow 3^{+}\right)$redox couple is $\sim 80 \mathrm{mV}$ at low scan rates and increases with increasing scan rate. This behavior points to quasi-reversibility of the viologen system in ionic liquid electrolyte. Further voltammetric data are provided in the supporting information. The calculated diffusion constant from these voltammetric data for $3 \cdot\left[\mathrm{PF}_{6}\right]_{2}$ in BMIM-OTf is $D$ $=3.41 \times 10^{-8} \mathrm{~cm}^{2} \mathrm{~s}^{-1}$ and a heterogeneous rate constant for the $3^{2+} \leftrightarrow 3^{+}$. redox couple of $k_{\text {het }}$ $=6 \times 10^{-4} \mathrm{~cm} \mathrm{~s}^{-1}$ has been estimated (see Supporting Information). 


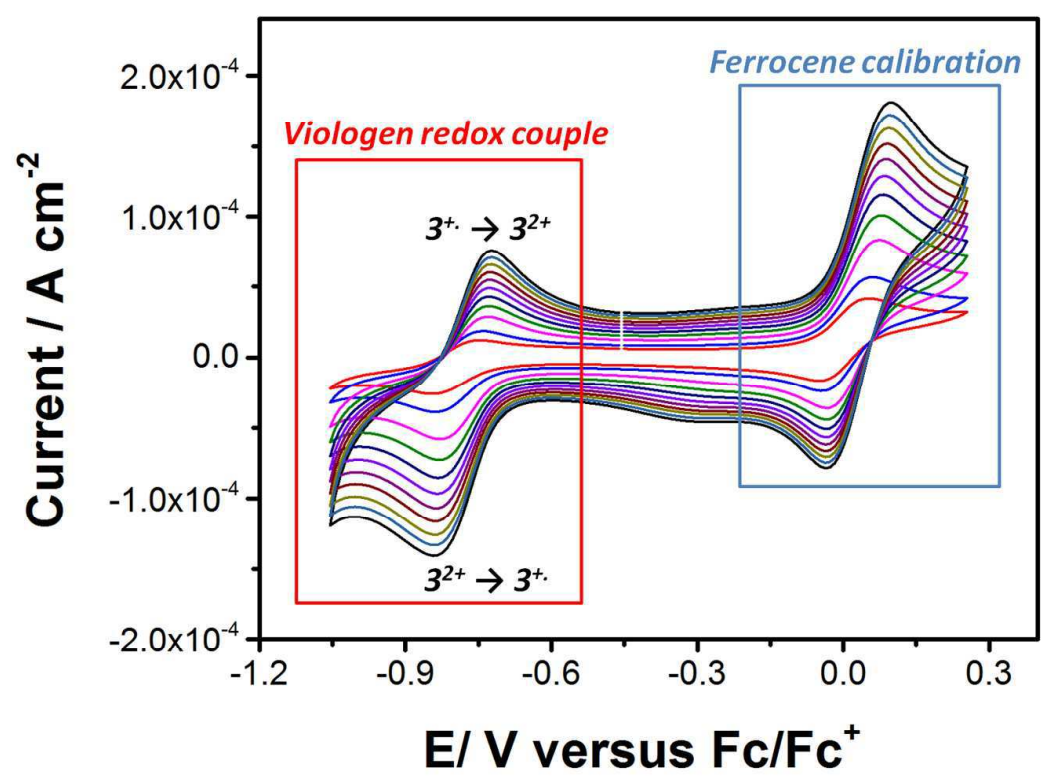

Figure 2: Cyclic voltammograms recorded for $3 \times 10^{-3} \mathrm{M}$ of the thioacetate protected form of $1^{2+}\left(3 \cdot\left[\mathrm{PF}_{6}\right]_{2}\right)$ in BMIM-OTf for 11 different scan rates and $\mathrm{Au}(111)$ working electrodes. The redox wave on the left corresponds to the viologen dication/radical cation redox couple, while the redox wave centered at $0 \mathrm{~V}$ arises from ferrocene added to the electrolyte as internal standard. The CVs were recorded at $0.05 \mathrm{~V} / \mathrm{s}, 0.1 \mathrm{~V} / \mathrm{s}$ and then in $0.1 \mathrm{~V}$ intervals to $1 \mathrm{~V} / \mathrm{s}$. 


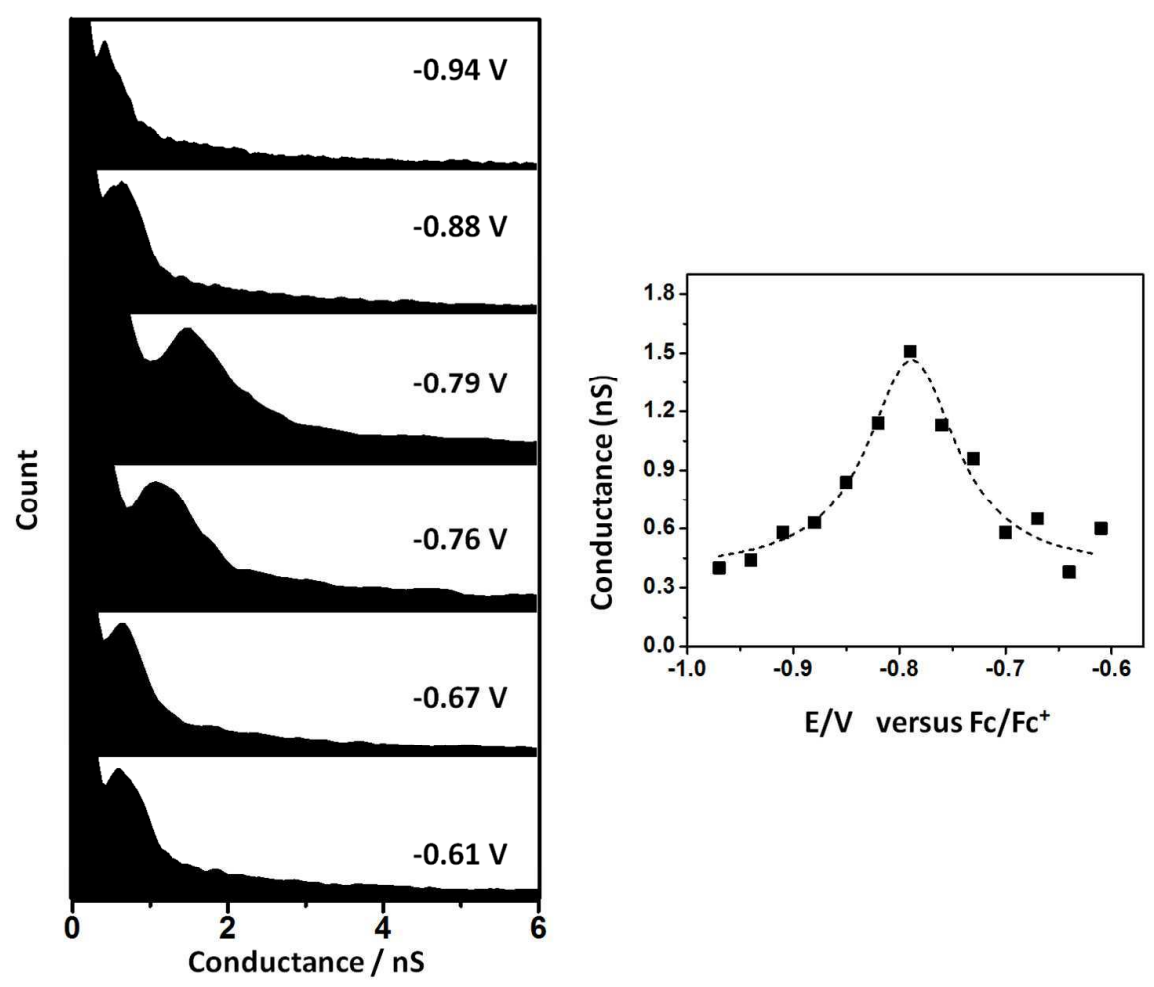

Figure 3 Left: conductance histograms recorded for molecular bridges formed from $\mathbf{1}^{2+}$ in ionic liquid electrolyte as a function of the marked electrochemical potential (versus $\mathrm{Fc} / \mathrm{Fc}^{+}$at $0.0 \mathrm{~V})$. Right: The single-molecule conductance of $1^{2+}$ versus electrochemical potential.

Figure 3 shows conductance histograms for molecular junctions formed from $1^{2+}$ recorded in BMIM-OTf using an STM and the $I(s)$ technique (see Experimental). These conductance histograms were recorded for the marked electrochemical potentials (versus $\mathrm{Fc} / \mathrm{Fc}^{+}$) and for a constant bias voltage of $0.6 \mathrm{~V}$. The peak of the conductance histograms shows a marked dependence on the electrochemical potential, as plotted in Figure 3 (right). This plot shows data recorded for 13 separate conductance histograms for 13 different electrochemical potentials. We have also recorded the cyclic voltammetric response (Figure 4a), conductance histograms (Figure 4b) and plotted electrochemically gated single-molecule conductance data (Figure 4c) for $\mathbf{2}^{2+}$, which features the trimethylsilylethynyl anchoring groups, in the same ionic liquid BMIM-OTf. ${ }^{68} 69$ Similar to $\mathbf{1}^{2+}$, compound $\mathbf{2}^{2+}$ also shows a single-molecule conductance maximum centered close to the equilibrium redox potential. 

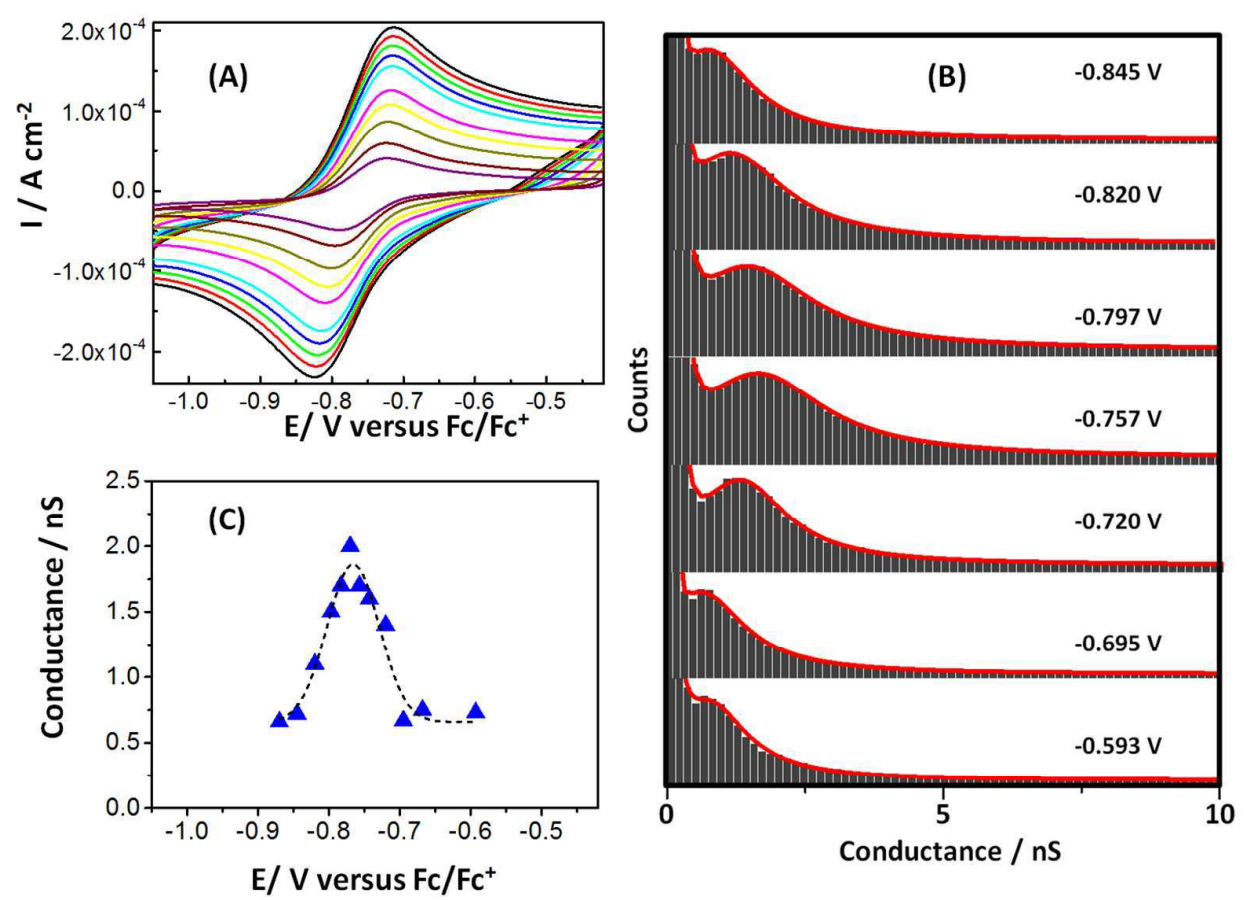

Figure $4(\mathrm{~A})$ : Cyclic voltammograms recorded for the first reduction of $2 \cdot\left[\mathrm{BF}_{4}\right]_{2}$ in BMIM-OTf. The CVs were run at $0.1 \mathrm{~V} \mathrm{~s}^{-1}$ intervals between 0.1 and $1.0 \mathrm{~V} \mathrm{~s}^{-1}$. (B) Conductance histograms recorded for molecular bridges formed from $2^{2+}$ in BMIM-OTf electrolyte as a function of the marked electrochemical potential (versus $\mathrm{Fc} / \mathrm{Fc}^{+}$at $0.0 \mathrm{~V}$ ). (C): Single molecule conductance of $\mathbf{2}^{2+}$ versus electrode potential in BMIM-OTf.

As indicated in the Introduction and described in greater detail below, in aqueous electrolyte $1^{2+}$ exhibits a gradual sigmoidal increase in the molecular conductance with applied gate potential over a wide electrochemical potential range of $\sim 1 \mathrm{~V}$. This strongly contrasts the bell-shaped conductance response of both $1^{2+}$ and $2^{2+}$ in electrochemically gated systems in ionic liquid electrolytes. In order to examine whether the electrolytic medium gives rise to differences in the electronic structure or conformation of the redox-active viologen cores upon reduction, which would be important considerations in rationalizing different gating behavior in the two media, we have studied the reduction of $2 \cdot\left[\mathrm{BF}_{4}\right]_{2}$ by UV/visible and IR spectroelectrochemistry in ionic liquid electrolytes. UV/visible spectroscopy is a very 
sensitive probe of the electronic and structural properties of the viologen radical cation, and UV/visible spectroelectrochemical studies of the viologen redox system in aqueous solution are very well described in the literature. ${ }^{70}$ On the other hand we are not aware of any reports of UV/visible and IR spectroelectrochemistry in ionic liquid electrolytes for viologen derivatives, or indeed any other electrochemical system. Details of the thin-layer spectroelectrochemical setup with ionic liquids and the stepwise reduction of $2 \cdot\left[\mathrm{BF}_{4}\right]_{2}$ to the corresponding radical cation and neutral viologen are given in the Experimental section and Supporting Information. UV/visible spectra recorded for $2 \cdot\left[\mathrm{BF}_{4}\right]_{2}$ in dry BMIM-OTf during the reduction of the dication (colorless) to the intensely colored radical cation are presented in Figure $5 a$, showing that reduction is accompanied by the growth of intense absorption envelopes at $\sim 400 \mathrm{~nm}$ and $\sim 610 \mathrm{~nm}$. Due to insufficient solubility of $2 \cdot\left[\mathrm{BF}_{4}\right]_{2}$ and $3 \cdot\left[\mathrm{PF}_{6}\right]_{2}$ in aqueous media, and for the purposes of comparison, the reduction of methyl viologen $\left(11 \cdot[\mathrm{Cl}]_{2}\right.$, Chart 2) has been investigated by UV/visible spectroelectrochemistry in both aqueous and ionic liquid media (Figure 5B and supporting information).

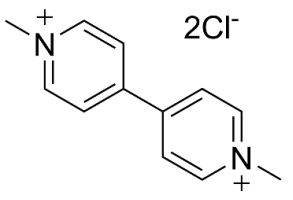

11. $[\mathrm{Cl}]_{2}$

Chart 2. The model methyl viologen dichloride, $11 \cdot[\mathrm{Cl}]_{2}$

The comparison of the viologen core reduction shown in Figures $5 a\left(2 \cdot\left[\mathrm{BF}_{4}\right]_{2}\right.$ in BMIM-OTf) and Figure $5 \mathrm{~B}\left(11 \cdot[\mathrm{Cl}]_{2}\right.$ in water) shows the growth of bands in very similar positions in the two different media. The spectroelectrochemically generated UV-Vis spectrum of the oneelectron reduced species $11^{+}$in water (Figure 5B) agree well with literature spectra of the methyl viologen radical cation, ${ }^{70}$ and is also similar to the UV-Vis spectrum of a reduced viologen appended to a triosmium cluster in $\mathrm{MeCN} .{ }^{71}$ The electronic absorption properties of the $\mathrm{V}^{2+} \mathrm{V}^{+}$. redox system therefore appear to be largely unaffected by the surrounding medium, with the only significance difference being the appearance of dimerization in the 
aqueous solution (see Figure 5 caption). This is further supported by UV/vis spectroelectrochemistry of $11 \cdot[\mathrm{Cl}]_{2}$ in BMIM-OTf which showed that the spectra of $2^{+}$and $11^{+}$ were near identical when recorded in the same medium (see Supporting Information). Further monitoring of the reduction of $2 \cdot\left[\mathrm{BF}_{4}\right]_{2}$ in BMIM-OTf by IR spectroscopy showed formation of a strong band at $1634 \mathrm{~cm}^{-1}$ (Figure 6 ) in good agreement with the $\mathrm{v}(\mathrm{C}=\mathrm{C}$ ) band reported $^{72}$ for a viologen radical cation. The intensity of the $\mathrm{v}(\mathrm{C} \equiv \mathrm{C})$ band at $2160 \mathrm{~cm}^{-1}$ in $2^{2+}$ also increases slightly as the radical cation $\mathbf{2}^{+}$is formed.
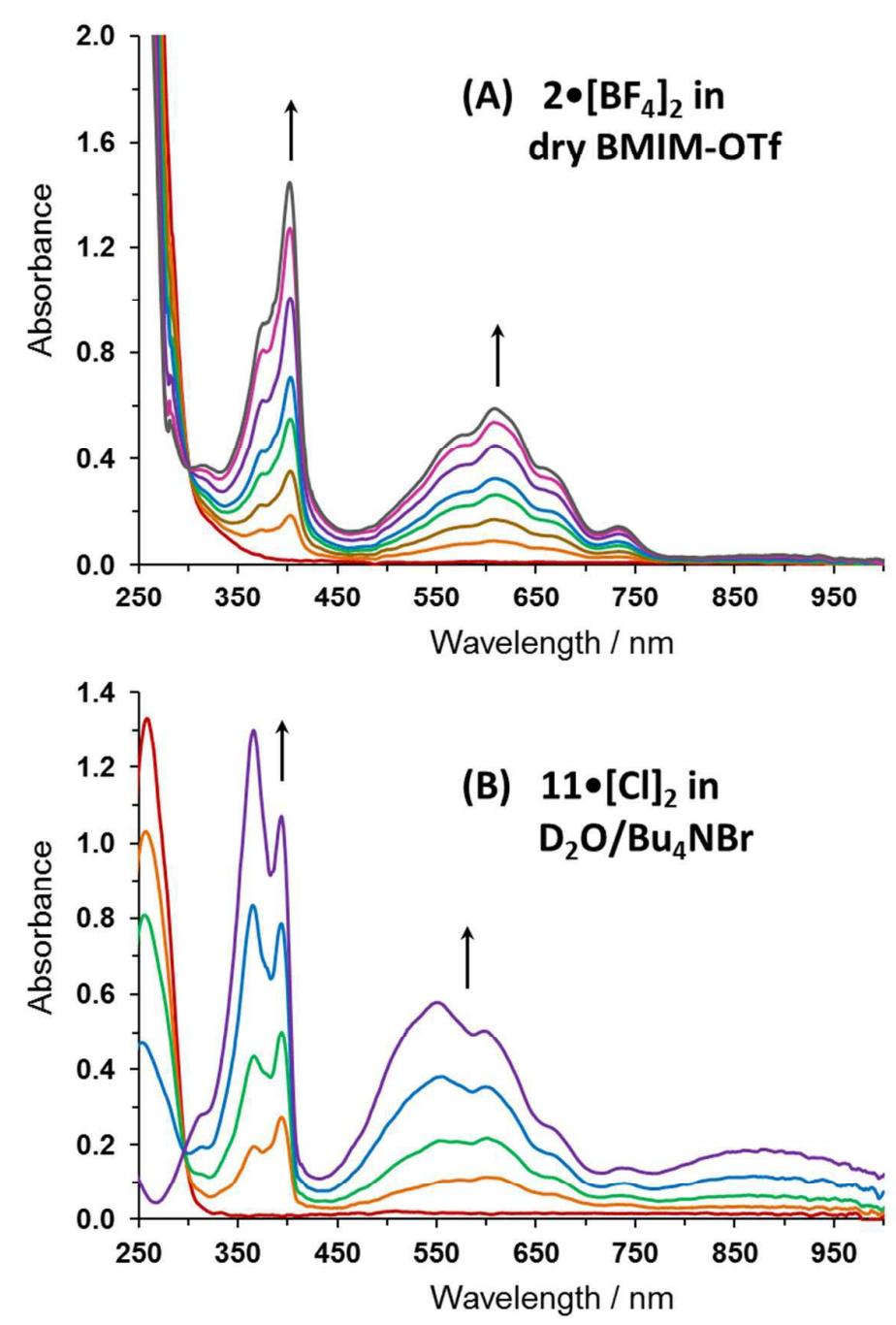

Figure 5. Reversible UV-Vis spectral changes accompanying the reduction of $(\mathrm{A})$ ca $2 \mathrm{mM}$ 2. $\left[\mathrm{BF}_{4}\right]_{2}$ in BMIM-OTf to its stable radical cation within an optically transparent thin layer electrochemical (OTTLE) cell $(I \sim 0.2 \mathrm{~mm})$ at $T=293 \mathrm{~K}$. (B) Reversible UV-Vis spectral 
changes accompanying the reduction of $2 \mathrm{mM} 11 \cdot[\mathrm{Cl}]_{2}$ in $\mathrm{D}_{2} \mathrm{O} / \mathrm{Bu}_{4} \mathrm{NBr}$ to a radical cation and its subsequent dimerization within an OTTLE cell at $T=293 \mathrm{~K}$. As the doublet around $\sim 380$ $\mathrm{nm}$ grows there is an inversion in intensities. This and the growing absorption at $\sim 870 \mathrm{~nm}$ are ascribed to dimerization of the radical cation in the aqueous electrolyte. These features are not observed in BMIM-OTf, see Figure S17. (The colors are to help distinguish the curves recorded during the reduction).

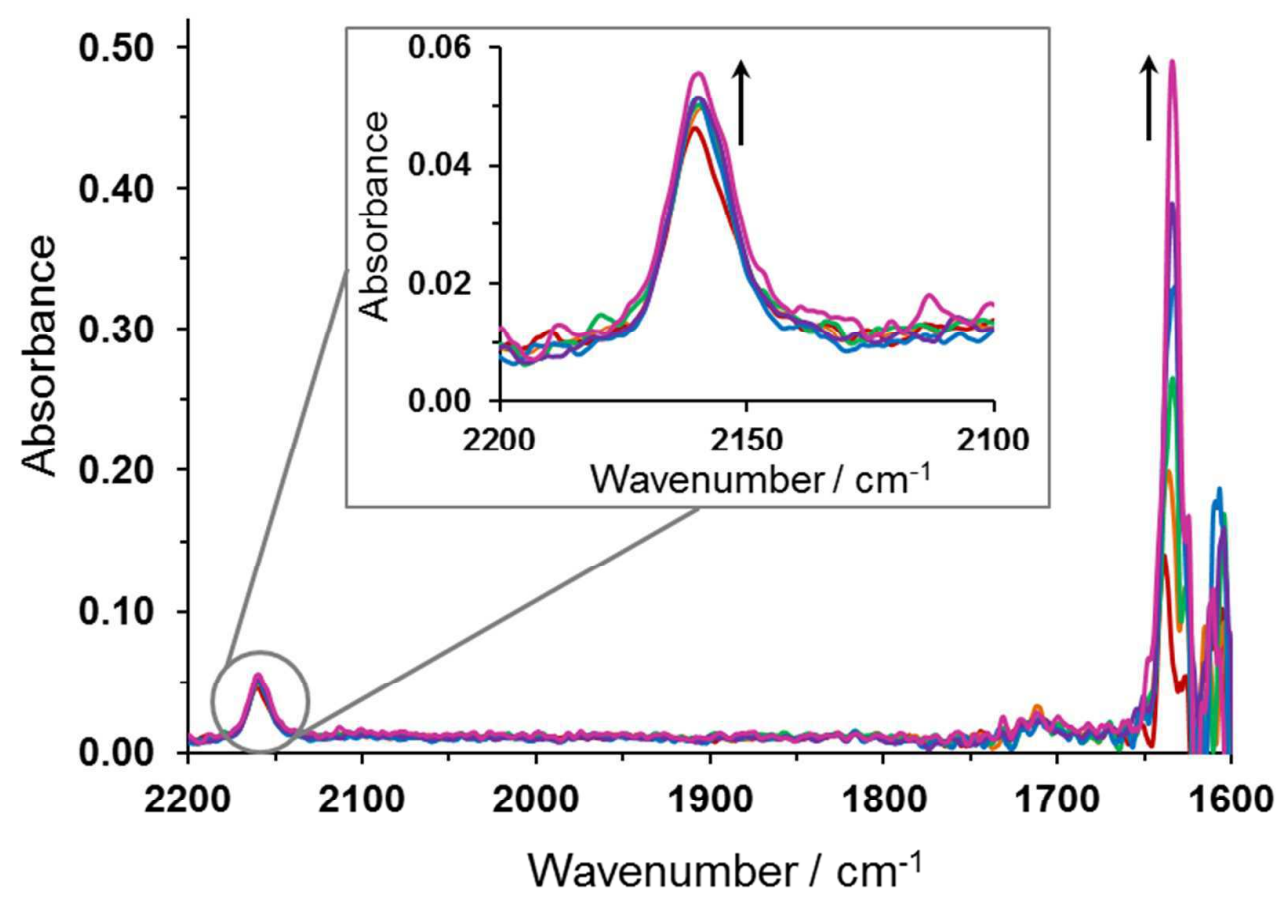

Figure 6. Reversible IR spectral changes accompanying the reduction of $10 \mathrm{mM} 2 \cdot\left[\mathrm{BF}_{4}\right]_{2}$ in BMIM-OTf to its stable radical cation within an OTTLE cell at $T=293 \mathrm{~K}$.

\section{- DISCUSSION}

A gradual sigmoidal increase in the molecular conductance has been observed previously in studies of electrochemically gated conductance of $1^{2+}$ in aqueous electrolytes, and attributed to a 'soft' electrochemical gating of the conductance response. ${ }^{10-13}$ In contrast, the single- 
molecule conductance data of $\mathbf{1}^{2+}$ and $\mathbf{2}^{2+}$ in ionic liquid both show a bell-shaped conductance versus potential form, with a clear maximum around the formal electrode potential of the $\mathrm{V}^{2+} / \mathrm{V}^{+}$. couple. ${ }^{10-13}$ This bell-shaped conductance versus potential form fits well to the two-step hopping model of Kuznetsov and Ulstrup with partial vibrational relaxation. The essence of the two-step process is that at, or close to, the equilibrium potential, both the oxidized and reduced forms of the molecular bridge contribute comparably to the current flow across the molecular junction. This model has been widely applied to charge transport across redox active molecular junctions and has also been used to justify enhanced current flow with redox active molecules in the tip-to-sample gap of an electrochemical STM. ${ }^{12,14,31,40-44,47,58,59,73,74}$ In this model charge is transported ("hops") through either the reduced or oxidized state of the molecule. In the first step the redox center has to reorganize through environmental and internal fluctuations so that the relevant molecular orbitals approach the Fermi level of one of the electrodes. Charge is transferred onto the redox center through a Frank Condon type transition. This is followed, in the adiabatic limit, by partial vibrational relaxation and subsequent charge transfer to the other electrode. In this partially relaxed state many electrons or holes can transfer across contributing to the enhancement in the junction current seen close to the reversible potential. By contrast, in the weak-coupling (diabatic) limit complete vibrational relaxation occurs before the electron/hole transfers to the second electrode and current enhancement is minimal. A schematic diagram illustrating the 2-step adiabatic Kuznetsov- Ulstrup used here is shown in Scheme 2. This illustrates the electrochemical nature of this process with step (1) representing the electron transfer from the left metal contact onto the redox group (reduction), step (2) representing the molecule and environment partially relaxing in the adiabatic limit and step (3) representing the electron transfer from the redox group (oxidation) onto the right contact. 


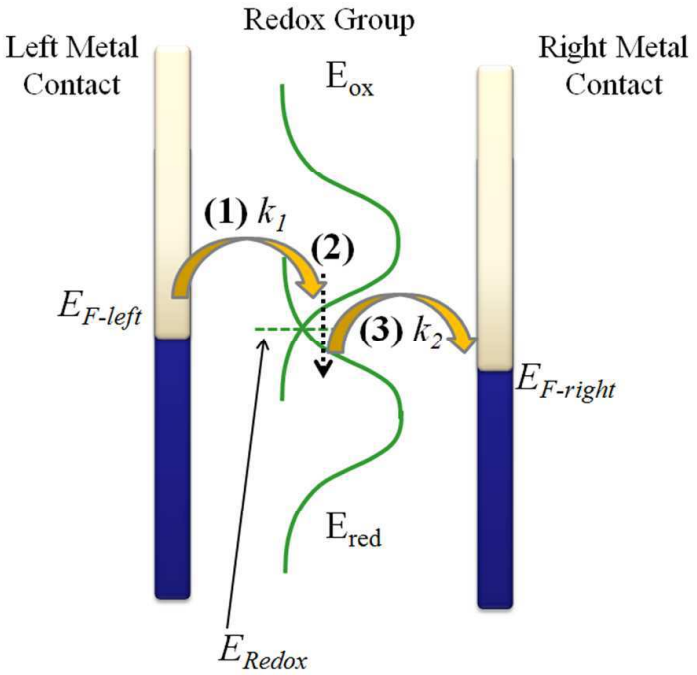

Scheme 2 This illustrates the 2-step adiabatic Kuznetsov- Ulstrup model used here, showing the two gold electrodes ("left" and "right") and the redox states of the molecular bridge in between. This proceeds with electron transfer from the left metal contact onto the redox group following pre-organization at and around the redox center The rate of electron transfer is represented by the electrochemical rate constant $k_{1}$ (step 1$)$. The now reduced redox group and surrounding environment partially relax (step 2). This is followed by electron transfer from the redox group (re-oxidation) onto the right contact with the electrochemical rate constant $k_{2}$ (step 3), resulting in a cascade of electron transfer between the electrodes through the partially relaxed state of the redox bridge.

In contrast to these two-step hopping mechanisms, resonant tunneling corresponds to the transferring charge populating the HOMO or LUMO on the bridge for such short time periods that no vibrational relaxation in the intermediate state occurs. Since both of these levels are displaced from the Fermi levels by the reorganization energy, this means that for resonant tunneling the current maximum is shifted by the reorganization (free) energy from the equilibrium potential. Since reorganization energies in such systems typically exceed a few hundred meV, and our ionic liquid data shows the maximum molecular conductance close to the $\mathrm{V}^{2+} \mathrm{V}^{+}$. reversible potential, we conclude that the data are best represented by a two-step 
hopping model. Furthermore, the considerable current enhancement points to the strong coupling (adiabatic) limit being more applicable. For these reasons we use below the adiabatic limit of the two-step model to describe the conductance versus electrochemical potential data. This consequently gives a maximum in the current versus electrochemical potential relation, with the maximum close to the equilibrium potential.

The absence of a maximum for molecular conductance versus electrochemical potential in the aqueous data previously reported would indicate that resonance of the gold Fermi levels with the redox center is not attained for the single molecule conductance configuration in the aqueous electrolyte. ${ }^{12}$ In this case, it has been previously argued that electron transfer in aqueous media is instead by superexchange through a significantly off-resonant and consequently empty redox level of the viologen $\left(\mathrm{V}^{2+}\right)$ moiety. The off-resonant oxidized state $\left(\mathrm{V}^{2+}\right)$ was thus taken to dominate the single-molecule conductance behavior of the viologen system in aqueous electrolytes. The gradual increase in conductance of the viologen system in aqueous electrolyte was rationalized with this superexchange model coupled with "softgating" to account for the conductance rise as the electrochemical potential is made more negative. ${ }^{12}$ The soft-gating was attributed to thermally accessible configurational fluctuations of the molecule and its environment which bring the molecular bridge into non-equilibrium configurations which promote more facile electron tunneling across the molecular junction. ${ }^{12}$ Leary et al. suggested that twisting about the central C-C bond of the $\mathrm{V}^{2+}$ moiety could be an important low-frequency mode in this respect. ${ }^{15}$

In our present study we offer another explanation based on our present observations that on changing the aqueous electrolyte to an ionic liquid electrolyte, the behavior changes from soft gating to hard gating. Our model below attributes the change in behavior to differences in the electrolyte gating properties of the ionic liquid compared to the aqueous electrolytes. This view is supported by the UV/vis spectroscopic data presented above which shows that the electronic absorption properties of viologen redox systems appear to be largely unaffected by the surrounding medium. 
To model the data we take the expression for the two-step hopping model as given by Kuznetsov and Ulstrup ${ }^{73}$ :

$j_{\text {enh }} \approx j_{0} \exp (-\lambda / 4 k T) \frac{\exp \left(e^{e\left|V_{\text {bias }}\right| / 4 k T}\right)}{\cosh \left(\frac{e(0.5-\gamma) V_{\text {bias }}-e \xi \eta}{2 k T}\right)} \quad$ Equation (1)

Here $j_{e n h}$ is the enhanced current following across the molecular junction as a result of charge transport following the two step adiabatic model. In this equation $\lambda$ is the total reorganization energy (both inner and outer-sphere), $k$ the Boltzmann constant, $V_{\text {bias }}$ the bias voltage, $T$ the temperature, $e$ the charge on an electron. The modeling parameters $\xi$ and $\gamma$ represent the fraction of the electrochemical potential and the fraction of the bias voltage dropped at the redox site, respectively. The parameter $\xi$ is referred to in the introduction as the "gating parameter" and it is a focus here for justifying the differences between the data recorded in aqueous and ionic liquid electrolytes. An expression for $j_{0}$ can be found elsewhere $^{73}$ :

$j_{0}=e n \omega_{e f f} / 2 \pi \quad$ Equation (2)

With

$n \approx e V_{\text {bias }}\left(\frac{1}{2 \kappa_{L} \rho_{L}}+\frac{1}{\kappa_{R} \rho_{R}}\right)^{-1} \quad$ Equation (3)

Where the $\kappa$ terms refer to the electron transmission coefficient and the $\rho$ terms the density of electronic states in the metal electrodes near the Fermi level. The subscripts $L$ and $R$ refer to the left and right electrodes, respectively. $\omega_{\text {eff }}$ is the effective nuclear vibrational frequencies. From these terms a numerical form can be obtained for $j_{\text {enh }}$ (see supporting information) which is used in the modeling.

Figure 7 a shows modeling of the conductance versus overpotential data recorded for $\mathbf{1}^{2+}$ in ionic liquid with the numerical form of equation (1). A gate coupling parameter of $\xi=1$ is used in this fitting with $\lambda=1.3 \mathrm{eV}$ and $\gamma=0.5$ (fitting errors are $\pm 0.2, \pm 0.03 \mathrm{eV}$ and \pm 0.1 in $\xi$ , $\lambda$ and $\gamma$, respectively. See supporting information for plot of conductance versus potential with error bars). Figure $7 \mathrm{~b}$ shows the $\mathbf{1}^{2+}$ data for aqueous phosphate buffer electrolytes and 
the modeling also using equation (1). Notice here that the electrochemical axis scale in Figure $7 \mathrm{~b}$ covers twice the voltage range of Figure $7 \mathrm{a}$, which highlights by comparison how broad the conductance rise is in aqueous electrolytes. This data from aqueous electrolytes, ${ }^{10,12}$ has not been previously modeled, and the present study provides opportunity to re-examine these existing data. The fitting parameters obtained here are $\xi=$ $0.2, \lambda=0.83 \mathrm{eV}$ and $\gamma=0.2$ (with fitting errors of $\pm 0.15, \pm 0.03 \mathrm{eV}$ and \pm 0.1 , respectively). As discussed elsewhere, ${ }^{14}$ a correlation is expected between the parameters $\xi$ and $\gamma$ in the narrow tunneling gap in which the Debye length is comparable to the tunneling gap width. For instance, at high ionic strength a high value for $\xi$ (e.g. 1) might be expected to correlate with a low value for $\gamma$ (e.g. 0.1). ${ }^{14}$ This is clearly not the case here and this discrepancy ${ }^{14}$ may be associated with the large size of the ionic liquid ions and the structuring and "layering" behavior which is known to take place for ionic liquid double layers. ${ }^{61}$
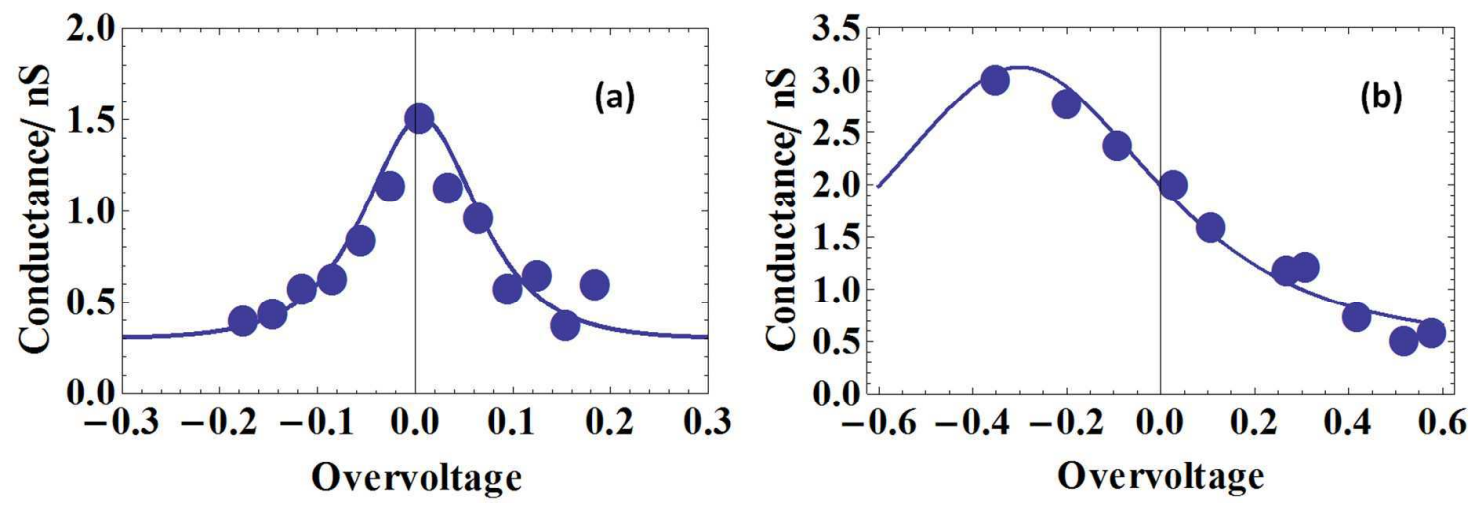

Figure $7 \quad$ Single molecule conductance data (blue circles) and fitting with equation 1 (solid blue lines), for $\mathbf{1}^{2+}$ in BMIM-OTf (a) and aqueous electrolytes (b). Experimental data in (b) was recorded in $0.1 \mathrm{M}$ phosphate buffer solution and is taken from refs. ${ }^{10,12}$

The single molecule conductance versus electrochemical potential data for $2^{2+}$ has also been modeled (see Supporting Information for data fitting). A design feature of $\mathbf{2}^{2+}$ is the incorporation of TMSE (TMSE, $-\mathrm{C} \equiv \mathrm{C}-\mathrm{SiMe}_{3}$ ) anchoring groups. TMSE groups for contacting to gold have been used in a number of previous molecular electronics studies of either molecular films or single molecules. ${ }^{68,69,75}$ The TMSE groups have a relatively large footprint 
and this, coupled with the nonlinear geometry of $2^{2+}$, is used here to hinder $\pi$-stacking and prevent formation of multi-molecular junctions in the gap. In particular, it is recognized in the literature that viologen dications and their radical cations have a propensity to stack in mixed-valence viologen salts. ${ }^{76}$ Reassuringly the electrochemical switching data for $\mathbf{2}^{2+}$ (Figure $4 b$ ) is similar to that for $1^{2+}$. The fitting parameters obtained from the $2^{2+}$ data are $\xi=$ $1, \lambda=1.3 \mathrm{eV}$ and $y=0.5$ (with fitting errors of $\pm 0.35, \pm 0.1 \mathrm{eV}$ and \pm 0.1 , respectively). These are comparable to the fitting parameters for $\mathbf{1}^{2+}$ in ionic liquid, showing again the highly effective gating in ionic liquid with $\xi=1$.

\section{- CONCLUSIONS}

Single-molecule electrochemical gating of viologen molecular bridges, studied here for the first time in ionic liquids, is very different from the behavior previously observed for aqueous electrolytes. In BMIM-OTf strong electrolyte gate coupling is observed with a calculated gate coupling efficiency of $100 \%$. Gate coupling efficiency for the viologen system in aqueous electrolytes is considerably lower at $20 \%$. This demonstrates the effectiveness of ionic liquids for single molecule electrolyte gating. Since the gating coupling is controlled by electrostatic interactions between the double layer gate and the redox bridge we note that its efficiency might be expected to depend on both these components, and therefore vary between redox systems. However, we note that a similar trend can be seen in the data for a redox active pyrrolo-tetrathiafulvalene bridge, ${ }^{14}$ with a gate coupling of $\xi=0.8-1$ in ionic liquid compared to a lower value $(\xi=0.5)$ in aqueous solutions.

UV/vis spectra show that the electronic absorption properties of viologen redox systems appear to be largely unaffected by the surrounding medium, supporting the notion that the differences observed between ionic liquid and aqueous environments arises from the electrolyte screening rather than electronic structure differences of the viologen core in these different media. Both the ionic liquid and aqueous electrolyte single molecule data for the viologen systems could be fitted with the standard two-step hopping model of Kuznetsov and 
Ulstrup with partial vibrational relaxation. The surprising high values of reorganization energy and uncorrelated bias voltage $(\gamma)$ and electrochemical $(\xi)$ potential drop parameters shows that new models will be eventually required to deal with the complexities of the molecular level structuring and screening properties of ionic liquid electrolytes.

\section{- EXPERIMENTAL METHODS}

\section{N,N'-Di-(4-(Trimethylsilylethynyl)benzyl)-4,4'-bipyridinium bis(tetrafluoroborate) $\left(2 \cdot\left[\mathrm{BF}_{4}\right]_{2}\right)$}

A mixture of 4,4'-bipyridine (100 mg, $640 \mu \mathrm{mol})$, compound 10 (428 mg, $1.60 \mathrm{mmol}$ ), acetonitrile $(30 \mathrm{~mL})$ and water $(3 \mathrm{~mL})$ was heated at reflux for $20 \mathrm{~h}$ and then allowed to cool to ambient temperature. After cooling, the creamy, powdery precipitate was isolated by filtration and the filtrate discarded. The collected precipitate $(350 \mathrm{mg})$ was mixed with ammonium tetrafluoroborate $(420 \mathrm{mg}, 4.01 \mathrm{mmol})$ in absolute ethanol $(53 \mathrm{~mL})$ and water $(11 \mathrm{~mL})$, and the mixture heated to reflux until a transparent, pale yellow solution was obtained, and then allowed to cool to ambient temperature. Cooling resulted in crystallisation of a white solid which was isolated by filtration and dried on the filter to afford $2 \cdot\left[\mathrm{BF}_{4}\right]_{2}$ in $82 \%$ yield as a white crystalline solid (260 mg, $369 \mu \mathrm{mol}) .{ }^{1} \mathrm{H}-\mathrm{NMR}\left(699.7 \mathrm{MHz}, \mathrm{CD}_{3} \mathrm{CN} / \mathrm{D}_{2} \mathrm{O}\right.$ 2:1 $(\mathrm{v} / \mathrm{v})): \delta=0.18\left(\mathrm{~s}, 18 \mathrm{H}, \mathrm{Si}\left(\mathrm{CH}_{3}\right)_{3}\right), 5.81\left(\mathrm{~s}, 4 \mathrm{H}, \mathrm{CH}_{2}\right), 7.44\left(\mathrm{~m}, 2 \mathrm{H}, \mathrm{H}-3 / \mathrm{H}-5, \mathrm{C}_{6} \mathrm{H}_{4}\right), 7.49(\mathrm{~m}$, $\left.2 \mathrm{H}, \mathrm{H}-3 / \mathrm{H}-5, \mathrm{C}_{6} \mathrm{H}_{4}\right), 8.40\left(\mathrm{~m}, 2 \mathrm{H}, \mathrm{H}-3 / \mathrm{H}-5, \mathrm{C}_{5} \mathrm{H}_{4} \mathrm{~N}\right), 9.01\left(\mathrm{~m}, 2 \mathrm{H}, \mathrm{H}-2 / \mathrm{H}-6, \mathrm{C}_{5} \mathrm{H}_{4} \mathrm{~N}\right) .{ }^{11} \mathrm{~B}-\mathrm{NMR}$ (224.5 MHz, $\left.\mathrm{CD}_{3} \mathrm{CN} / \mathrm{D}_{2} \mathrm{O} 2: 1(\mathrm{v} / \mathrm{v})\right): \delta=-1.4 .{ }^{13} \mathrm{C}-\mathrm{NMR}\left(175.9 \mathrm{MHz}, \mathrm{CD}_{3} \mathrm{CN} / \mathrm{D}_{2} \mathrm{O} 2: 1(\mathrm{v} / \mathrm{v})\right): \delta$ $=-0.2\left(\mathrm{Si}\left(\mathrm{CH}_{3}\right)_{3}\right), 65.1\left(\mathrm{CH}_{2}\right), 97.2(\mathrm{C} \equiv \mathrm{C}-\mathrm{Si}), 104.9(\mathrm{C} \equiv \mathrm{C}-\mathrm{Si}), 125.2\left(\mathrm{C}-4, \mathrm{C}_{6} \mathrm{H}_{4}\right), 128.4(\mathrm{C}-$ $\left.3 / C-5, \mathrm{C}_{5} \mathrm{H}_{4} \mathrm{~N}\right), 130.5\left(C-3 / C-5, \mathrm{C}_{6} \mathrm{H}_{4}\right), 133.6\left(C-2 / C-6, \mathrm{C}_{6} \mathrm{H}_{4}\right), 134.1\left(C-1, \mathrm{C}_{6} \mathrm{H}_{4}\right), 146.6(C-$ 2/C-6, $\left.\mathrm{C}_{5} \mathrm{H}_{4} \mathrm{~N}\right), 151.2\left(\mathrm{C}-4, \mathrm{C}_{5} \mathrm{H}_{4} \mathrm{~N}\right) .{ }^{19} \mathrm{~F}-\mathrm{NMR}\left(564.3 \mathrm{MHz}, \mathrm{CD}_{3} \mathrm{CN} / \mathrm{D}_{2} \mathrm{O} 2: 1(\mathrm{v} / \mathrm{v})\right): \delta=-$ $151.24\left(\mathrm{~m}, 0.8 \mathrm{~B},{ }^{11} \mathrm{~B} F_{4}\right),-151.19\left(\mathrm{~m}, 0.2 \mathrm{~B},{ }^{10} \mathrm{~B} F_{4}\right) .{ }^{29} \mathrm{Si}-\mathrm{NMR}\left(139.0 \mathrm{MHz}, \mathrm{CD}_{3} \mathrm{CN} / \mathrm{D}_{2} \mathrm{O} 2: 1\right.$ $(\mathrm{v} / \mathrm{v})): \delta=-17.1$. ESI-MS: $m / z(\%) 617(17)\left[\mathrm{M}-\mathrm{BF}_{4}\right]^{+}, 343(80), 187$ (100). Anal. calcd for $\mathrm{C}_{34} \mathrm{H}_{38} \mathrm{~B}_{2} \mathrm{~F}_{8} \mathrm{~N}_{2} \mathrm{Si}_{2}$ C: $57.97 ; \mathrm{H}: 5.44 ; \mathrm{N}: 3.98$ found C: $57.83 ; \mathrm{H}: 5.46 ; \mathrm{N}: 4.02$.

\section{4-(Trimethylsilylethynyl)benzyl alcohol (9).}


Ethynyltrimethylsilane (923 mg, $9.40 \mathrm{mmol})$, 4-iodobenzyl alcohol $(2.00 \mathrm{~g}, 8.55 \mathrm{mmol})$, $\mathrm{PdCl}_{2}\left(\mathrm{PPh}_{3}\right)_{2}(60.0 \mathrm{mg}, 85.5 \mu \mathrm{mol})$ and copper(I) iodide $(16.0 \mathrm{mg}, 85.5 \mu \mathrm{mol})$ were dissolved in triethylamine $(50 \mathrm{~mL})$ at $20^{\circ} \mathrm{C}$ and the reaction mixture was stirred at this temperature for $16 \mathrm{~h}$. The solvent was then removed under reduced pressure and the residue was purified by flash column chromatography (silica gel; eluent, hexanes/ethyl acetate $(80: 20(\mathrm{v} / \mathrm{v})))$ to give a yellow oil. This oil was crystallised from hexanes $\left(5 \mathrm{~mL}\right.$, cooling at $\left.-20^{\circ} \mathrm{C}\right)$ to afford 3 in $67 \%$ yield $(1.17 \mathrm{~g}, 8.55 \mathrm{mmol})$ as a colorless crystalline solid. ${ }^{1} \mathrm{H}-\mathrm{NMR}(699.7 \mathrm{MHz}$ $\left.\mathrm{CDCl}_{3}\right): \delta=0.25\left(\mathrm{~s}, 9 \mathrm{H}, \mathrm{Si}\left(\mathrm{CH}_{3}\right)_{3}\right), 4.69\left(\mathrm{~s}, 2 \mathrm{H}, \mathrm{CH}_{2}\right), 7.30\left(\mathrm{~d}, 2 \mathrm{H},{ }^{3} J_{\mathrm{H}-\mathrm{H}}=8.3 \mathrm{~Hz}, \mathrm{H}-3 / \mathrm{H}-5\right.$, $\left.\mathrm{C}_{6} \mathrm{H}_{4}\right), 7.46\left(\mathrm{~d}, 2 \mathrm{H},{ }^{3} \mathrm{~J}_{\mathrm{H}-\mathrm{H}}=8.3 \mathrm{~Hz}, \mathrm{H}-2 / \mathrm{H}-6, \mathrm{C}_{6} \mathrm{H}_{4}\right) .{ }^{13} \mathrm{C}-\mathrm{NMR}\left(175.9 \mathrm{MHz}, \mathrm{CDCl}_{3}\right): \delta=0.1$

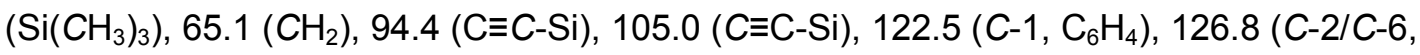
$\left.\mathrm{C}_{6} \mathrm{H}_{4}\right), 123.3\left(\mathrm{C}-3 / \mathrm{C}-5, \mathrm{C}_{6} \mathrm{H}_{4}\right), 141.3\left(\mathrm{C}-4, \mathrm{C}_{6} \mathrm{H}_{4}\right) .{ }^{29} \mathrm{Si}-\mathrm{NMR}\left(139.0 \mathrm{MHz}, \mathrm{CDCl}_{3}\right): \delta=-17.8$. El-MS: $m / z(\%) 204(22)\left[\mathrm{M}^{+}\right], 189(100)\left[\mathrm{M}^{+}-\mathrm{CH}_{3}\right] .{ }^{1} \mathrm{H}$ and ${ }^{13} \mathrm{C}$ NMR data were consistent with those reported in the literature. ${ }^{77}$

\section{4-(Trimethylsilylethynyl)benzyl bromide (10)}

Bromine $\left(1.10 \mathrm{~g}, 6.87 \mathrm{mmol}\right.$ of $\left.\mathrm{Br}_{2}\right)$ was added dropwise at $0{ }^{\circ} \mathrm{C}$ to a stirred solution of triphenylphosphine $(1.89 \mathrm{~g}, 7.15 \mathrm{mmol})$ in dichloromethane $(20 \mathrm{~mL})$. On completion of this addition, a solution of compound 9 ( $1.17 \mathrm{~g}, 5.72 \mathrm{mmol})$ and imidazole (467 $\mathrm{mg}, 6.87 \mathrm{mmol})$ in dichloromethane $(7 \mathrm{~mL})$ was added to the solution of bromine triphenylphosphine complex via cannula at $0{ }^{\circ} \mathrm{C}$. Subsequently, the reaction mixture was allowed to warm to ambient temperature, stirred for $3 \mathrm{~h}$ at this temperature and concentrated in vacuo. Diethyl ether $(30 \mathrm{~mL})$ was added to the residue and the flask was placed into an ultrasound bath until a homogeneous beige precipitate in a pale yellow solution was obtained. The precipitate was removed by filtration and discarded. The filtrate was concentrated under reduced pressure, hexanes $(30 \mathrm{~mL})$ were added to the residue and the flask was once again placed into an ultrasound bath until a homogeneous white precipitate in a pale yellow solution was obtained. The precipitate was removed by filtration and the filtrate concentrated to give a pale yellow oil; this crystallised on standing to afford 10 in $90 \%$ yield $(1.38 \mathrm{~g}, 5.17 \mathrm{mmol})$ as 
a yellow tinged crystalline solid. ${ }^{1} \mathrm{H}-\mathrm{NMR}\left(699.7 \mathrm{MHz} \mathrm{CDCl}_{3}\right): \delta=0.25\left(\mathrm{~s}, 9 \mathrm{H}, \mathrm{Si}\left(\mathrm{CH}_{3}\right)_{3}\right)$, $4.46\left(\mathrm{~s}, 2 \mathrm{H}, \mathrm{CH}_{2}\right), 7.32\left(\mathrm{~d}, 2 \mathrm{H},{ }^{3} \mathrm{~J}_{\mathrm{H}-\mathrm{H}}=8.3 \mathrm{~Hz}, \mathrm{H}-3 / \mathrm{H}-5, \mathrm{C}_{6} \mathrm{H}_{4}\right), 7.43\left(\mathrm{~d}, 2 \mathrm{H},{ }^{3} \mathrm{~J}_{\mathrm{H}-\mathrm{H}}=8.3 \mathrm{~Hz}\right.$, $\left.H-2 / H-6, \mathrm{C}_{6} \mathrm{H}_{4}\right) .{ }^{13} \mathrm{C}-\mathrm{NMR}\left(175.9 \mathrm{MHz}, \mathrm{CDCl}_{3}\right): \delta=0.1\left(\mathrm{Si}\left(\mathrm{CH}_{3}\right)_{3}\right), 33.1\left(\mathrm{CH}_{2}\right), 95.4(\mathrm{C} \equiv \mathrm{C}-\mathrm{Si})$, 104.6 (CEC-Si), $123.4\left(C-1, \mathrm{C}_{6} \mathrm{H}_{4}\right), 129.1\left(C-2 / C-6, \mathrm{C}_{6} \mathrm{H}_{4}\right), 132.5\left(C-3 / C-5, \mathrm{C}_{6} \mathrm{H}_{4}\right), 138.1(C-4$, $\left.\mathrm{C}_{6} \mathrm{H}_{4}\right) .-{ }^{29} \mathrm{Si}-\mathrm{NMR}\left(139.0 \mathrm{MHz}, \mathrm{CDCl}_{3}\right): \delta=-17.6$. El-MS: $m / z(\%) 268(25)\left[\mathrm{M}^{+}\right], 253(73)$ $\left[\mathrm{M}^{+}-\mathrm{CH}_{3}\right], 187(100)\left[\mathrm{M}^{+}-\mathrm{Br}\right] .{ }^{1} \mathrm{H}$ and ${ }^{13} \mathrm{C}$ NMR data were consistent with those reported in the literature. ${ }^{78}$

\section{Cyclic Voltammetry}

1-Butyl-3-methylimidazolium triflate, BMIM-OTf (loLiLyt, 99\%), was dried for 24 hours under vacuum prior to use $\left(120^{\circ} \mathrm{C}\right)$. Cyclic voltammetry of the thioacetate protected form of $1^{2+}$ $\left(3 \cdot\left[\mathrm{PF}_{6}\right]_{2}\right)$ was recorded for $\mathrm{Au}(111)$ substrate. This gold electrode was immersed for $24 \mathrm{~h}$ in a solution of $3 \cdot\left[\mathrm{PF}_{6}\right]_{2}(7.5 \mathrm{mM}$ in methanol) then it was cleaned with methanol and Milli-Q water (Millipore), and dried in a stream of $\mathrm{N}_{2}$ gas. Pt wires were used as counter and quasi reference electrodes. Before measurements a drop of diluted ferrocene was added to use as internal reference. Measurements were carried out in dried BMIM-OTf and under $\mathrm{N}_{2}$ flow. The concentration of $3 \cdot\left[\mathrm{PF}_{6}\right]_{2}$ in BMIM-OTf was $3 \times 10^{-3} \mathrm{M}$.

Cyclic voltammetry of $\mathbf{2} \cdot\left[\mathrm{BF}_{4}\right]_{2}$ in BMIM-OTf was recorded for a $7.5 \mathrm{mM}$ solution of the analyte in BMIM-OTf. This solution was prepared by first dissolving $2 \cdot\left[\mathrm{BF}_{4}\right]_{2}$ in methanol, and then adding this solution to the ionic liquid. The methanol was removed by heating the solution at $\sim 100^{\circ} \mathrm{C}$ for $1.5 \mathrm{~h}$ with a nitrogen sparge. The working electrode was a $\mathrm{Au}(111)$ bead, with a hanging meniscus, while the counter and reference electrodes were $0.5 \mathrm{~mm} \mathrm{Pt}$ wire. All potentials were determined against an internal $\mathrm{Fc} / \mathrm{Fc}^{+}$reference added after the experiment.

\section{Single-Molecule Conductance Measurements}


The STM based $I(s)$ method as described in references ${ }^{10,79}$ has been used to obtain singlemolecule conductance values as a function of electrode potential. In brief, an STM tip is approached close to the gold surface so that the target molecule can bind between the gold tip and the substrate. The tip is then rapidly retracted and a current $(I)$ versus distance $(s)$ curve recorded. Hundreds of such junction making and breaking curves are analyzed statistically in histograms to yield the conductance. To avoid ambiguity caused by the inclusion of retraction traces where no junction is formed, we constructed conductance histograms from retraction traces displaying plateaus and steps, which are synonymous with molecular junction formation. The STM- $I(s)$ measurements were performed with flameannealed Au substrate. For the $1^{2+}$ measurements under electrochemical potential control the substrate was immersed for 5 minutes in a solution of $3 \cdot\left[\mathrm{PF}_{6}\right]_{2}(7.5 \mathrm{mM}$ in methanol), then it was cleaned with methanol and Milli-Q water (Millipore) and dried in a stream of $\mathrm{N}_{2}$. It has been previously shown that adsorbed layers of thiols can be formed by direct adsorption from the corresponding thioacetate protected molecules in ionic liquid solutions. ${ }^{14}$

Measurements were carried out in $\mathrm{N}_{2}$ atmosphere using the described substrate and in a 1.5 $\mathrm{mM}$ solution of $3 \cdot\left[\mathrm{PF}_{6}\right]_{2}$ in the ionic liquid (BMIM-OTf). Pt wires were used as counter and reference electrodes. The STM tip was an etched gold wire. Set point parameters were $I_{0}$ $=20 \mathrm{nA}$ and $U_{t}=0.6 \mathrm{~V}$.

\section{Spectroelectrochemistry}

UV-Vis and IR spectroelectrochemical experiments were carried out using an optically transparent thin layer spectroelectrochemical (OTTLE) cell ${ }^{80}$ equipped with $\mathrm{CaF}_{2}$ optical windows, Pt minigrid working and auxiliary electrodes, and an Ag wire pseudo-reference electrode. UV-Vis spectroelectrochemistry was recorded with a Scinco S3100 diode array spectrophotometer. IR spectroelectrochemical data were recorded using a Bruker Vertex 70v FT-IR spectrometer equipped with a DLaTGS detector working at the resolution of $1 \mathrm{~cm}^{-}$ 1. The spectroelectrochemical measurements were monitored using thin-layer cyclic 
voltammetry performed with an EmStat-3 potentiostat (PalmSens BV, The Netherlands) operated with the PSTrace v.4.2 software.

Solutions of 2. $\left[\mathrm{BF}_{4}\right]_{2}$ in BMIM-OTf contained $2 \mathrm{mM}$ (UV-Vis spectroelectrochemistry) or 10 $\mathrm{mM}$ (IR spectroelectrochemistry) 2.[BF $]_{2}$ and were prepared as follows. BMIM-OTf (loLiLyt, $99 \%$ ) was heated in a Schlenk vessel under stirring for $>18 \mathrm{~h}$ at $120^{\circ} \mathrm{C}$ under high vacuum $2 \cdot\left[\mathrm{BF}_{4}\right]_{2}$ was partly dissolved in a few drops of ethanol and hot BMIM-OTf was added with a vacuum tight Hamilton syringe to give a homogenous solution. The resulting solution was sparged with dry argon at $120^{\circ} \mathrm{C}$ for ca $2 \mathrm{~h}$.

Supporting Information Available: General synthetic methods and synthetic details for $\mathbf{1}^{2+}$, N,N'-Di-(6-(thioacetyl)hexyl)-4,4'-bipyridinium bis(hexafluorophosphate) $\left(3 \cdot\left[\mathrm{PF}_{6}\right]_{2}\right), N, N^{\prime}-\mathrm{Di}$ (6-(thioacetyl)hexyl)-4,4'-bipyridinium dibromide $\left(3 \cdot[\mathrm{Br}]_{2}\right)$ and $S$-(6-bromohexyl) ethanethioate. Electrochemistry of $2\left(\mathrm{BF}_{4}\right)_{2}$ in acetonitrile electrolytes and of $2\left(\mathrm{BF}_{4}\right)_{2}$ in ionic liquid, the two step model equations and $2^{2+}$ conductance data, break-off distance data, diffusion coefficients and heterogeneous rate constants, collected UV-Vis and IR spectra, plots with error bars for $\mathbf{1}^{2+}$ and $\mathbf{2}^{2+}$ data and bias voltage data. This material is available free of charge via the Internet at http://pubs.acs.org.

Additional supporting data files at DOI: http://datacat.liverpool.ac.uk/id/eprint/62

\section{- ACKNOWLEDGEMENTS}

R.J.N. and S.J.H. thank EPSRC for funding (grant EP/H035184/1 and EP/K007785/1). S.M. and P.C. are grateful for financial assistance from Ministerio de Economía y Competitividad from Spain in the framework of projects CTQ2012-33198 and CTQ2013-50187-EXP and support from DGA and Fondos Feder for funding Platon research group. P.J.L. thanks EPSRC for funding and also gratefully acknowledges support from the Australian Research Council (DP 140100855) and the award of a Future Fellowship (FT120100073). H.M.O is grateful for financial assistance from Secretaría Nacional de Educación Superior, Ciencia, 
Tecnología e Innovación from Ministerio de Educación (Ecuador). F.H. thanks EPSRC for funding (EP/K00753X/1) and acknowledges the University of Reading for the support of the Reading Spectroelectrochemistry center (University Project D14-015 Spectroelectrochemical Cells).

\section{REFERENCES}

(1) van der Molen, S. J.; Liljeroth, P. Journal of Physics-Condensed Matter 2010, 22, 133001.

(2) Song, H.; Kim, Y.; Jang, Y. H.; Jeong, H.; Reed, M. A.; Lee, T. Nature 2009, 462, 1039.

(3) Kruger, M.; Buitelaar, M. R.; Nussbaumer, T.; Schonenberger, C.; Forro, L. Appl. Phys. Lett. 2001, 78, 1291.

(4) Rosenblatt, S.; Yaish, Y.; Park, J.; Gore, J.; Sazonova, V.; McEuen, P. L. Nano Lett. 2002, 2, 869.

(5) Meulenkamp, E. A. J. Phys. Chem. B 1999, 103, 7831.

(6) Ye, J. T.; Inoue, S.; Kobayashi, K.; Kasahara, Y.; Yuan, H. T.; Shimotani, H.; Iwasa, Y. Nat. Mater. 2010, 9, 125.

(7) Yuan, H.; Shimotani, H.; Tsukazaki, A.; Ohtomo, A.; Kawasaki, M.; Iwasa, Y. Adv. Funct. Mater. 2009, 19, 1046.

(8) White, H. S.; Kittlesen, G. P.; Wrighton, M. S. J. Am. Chem. Soc. 1984, 106, 5375.

(9) Nichols, R. J.; Higgins, S. J. "Single Molecular Electrochemistry within an STM" in "Electrocatalysis - Theoretical Foundations and Model Experiments", Advances in Electrochemical Science and Engineering, Volume XIV, Publishers Wiley-VCH, Editors L. Kibler, R.C. Alkire, D.M. Kolb and J. Lipkowski.

(10) Haiss, W.; van Zalinge, H.; Higgins, S. J.; Bethell, D.; Hobenreich, H.; Schiffrin, D. J.; Nichols, R. J. J. Am. Chem. Soc. 2003, 125, 15294.

(11) Li, Z. H.; Pobelov, I.; Han, B.; Wandlowski, T.; Blaszczyk, A.; Mayor, M. Nanotechnology 2007, $18,044018$.

(12) Haiss, W.; Albrecht, T.; van Zalinge, H.; Higgins, S. J.; Bethell, D.; Hoebenreich, H.; Schiffrin, D. J.; Nichols, R. J.; Kuznetsov, A. M.; Zhang, J.; Chi, Q.; Ulstrup, J. J. Phys. Chem. B 2007, 111, 6703.

(13) Li, Z.; Han, B.; Meszaros, G.; Pobelov, I.; Wandlowski, T.; Blaszczyk, A.; Mayor, M. Faraday Discuss. 2006, 131, 121.

(14) Kay, N. J.; Higgins, S. J.; Jeppesen, J. O.; Leary, E.; Lycoops, J.; Ulstrup, J.; Nichols, R. J. J. Am. Chem. Soc. 2012, 134, 16817.

(15) Leary, E.; Higgins, S. J.; van Zalinge, H.; Haiss, W.; Nichols, R. J.; Nygaard, S.; Jeppesen, J. O.; Ulstrup, J. J. Am. Chem. Soc. 2008, 130, 12204.

(16) Chen, F.; He, J.; Nuckolls, C.; Roberts, T.; Klare, J. E.; Lindsay, S. Nano Lett. 2005, 5, 503.

(17) He, J.; Chen, F.; Lindsay, S.; Nuckolls, C. Appl. Phys. Lett. 2007, 90, 072112.

(18) He, J.; Forzani, E. S.; Nagahara, L. A.; Tao, N. J.; Lindsay, S. Journal of Physics-Condensed Matter 2008, 20, 374120.

(19) Xu, B. Q. Q.; Li, X. L. L.; Xiao, X. Y. Y.; Sakaguchi, H.; Tao, N. J. J. Nano Lett. 2005, 5, 1491.

(20) Xiao, X. Y.; Nagahara, L. A.; Rawlett, A. M.; Tao, N. J. J. Am. Chem. Soc. 2005, 127, 9235.

(21) He, J.; Fu, Q.; Lindsay, S.; Ciszek, J. W.; Tour, J. M. J. Am. Chem. Soc. 2006, 128, 14828.

(22) Kolivoska, V.; Moreno-Garcia, P.; Kaliginedi, V.; Hong, W.; Mayor, M.; Weibel, N.; Wandlowski, T. Electrochim. Acta 2013, 110, 709.

(23) Xiao, X. Y.; Brune, D.; He, J.; Lindsay, S.; Gorman, C. B.; Tao, N. J. Chem. Phys. 2006, 326, 138. 
(24) Darwish, N.; Diez-Perez, I.; Guo, S. Y.; Tao, N. J.; Gooding, J. J.; Paddon-Row, M. N. J. Phys. Chem. C 2012, 116, 21093.

(25) Darwish, N.; Diez-Perez, I.; Da Silva, P.; Tao, N. J.; Gooding, J. J.; Paddon-Row, M. N. Angew. Chem. Int. Ed. 2012, 51, 3203.

(26) Baghernejad, M.; Zhao, X.; Ornso, K. B.; Fueeg, M.; Moreno-Garcia, P.; Rudnev, A. V.; Kaliginedi, V.; Vesztergom, S.; Huang, C.; Hong, W.; Broekmann, P.; Wandlowski, T.; Thygesen, K. S.; Bryce, M. R. J. Am. Chem. Soc. 2014, 136, 17922.

(27) Xu, B. Q.; Xiao, X. Y.; Yang, X. M.; Zang, L.; Tao, N. J. J. Am. Chem. Soc. 2005, 127, 2386.

(28) Li, X.; Hihath, J.; Chen, F.; Masuda, T.; Zang, L.; Tao, N. J. Am. Chem. Soc. 2007, 129, 11535.

(29) Li, X. L.; Xu, B. Q.; Xiao, X. Y.; Yang, X. M.; Zang, L.; Tao, N. J. Faraday Discuss. 2006, 131, 111.

(30) Li, C.; Stepanenko, V.; Lin, M.-J.; Hong, W.; Wuerthner, F.; Wandlowski, T. Physica Status Solidi B-Basic Solid State Physics 2013, 250, 2458.

(31) Li, C.; Mishchenko, A.; Li, Z.; Pobelov, I.; Wandlowski, T.; Li, X. Q.; Wuerthner, F.; Bagrets, A.; Evers, F. Journal of Physics-Condensed Matter 2008, 20, 374122.

(32) Visoly-Fisher, I.; Daie, K.; Terazono, Y.; Herrero, C.; Fungo, F.; Otero, L.; Durantini, E.; Silber, J. J.; Sereno, L.; Gust, D.; Moore, T. A.; Moore, A. L.; Lindsay, S. M. Proc. Nat. Acad. Sci. U.S.A. 2006, $103,8686$.

(33) Li, Z.; Li, H.; Chen, S.; Froehlich, T.; Yi, C.; Schoenenberger, C.; Calame, M.; Decurtins, S.; Liu, S.-X.; Borguet, E. J. Am. Chem. Soc. 2014, 136, 8867.

(34) Li, C.; Mishchenko, A.; Wandlowski, T. Unimolecular and Supramolecular Electronics li: Chemistry and Physics Meet at Metal-Molecule Interfaces 2012, 313, 121.

(35) Capozzi, B.; Chen, Q.; Darancet, P.; Kotiuga, M.; Buzzeo, M.; Neaton, J. B.; Nuckolls, C.; Venkataraman, L. Nano Lett. 2014, 14, 1400.

(36) Brooke, R. J.; Jin, C.; Szumski, D. S.; Nichols, R. J.; Mao, B.-W.; Thygesen, K. S.; Schwarzacher, W. Nano Lett. 2015, 15, 275.

(37) Tao, N. J. Phys. Rev. Lett. 1996, 76, 4066.

(38) Wassel, R. A.; Credo, G. M.; Fuierer, R. R.; Feldheim, D. L.; Gorman, C. B. J. Am. Chem. Soc. 2004, 126, 295.

(39) Zhang, J. D.; Chi, Q. J.; Albrecht, T.; Kuznetsov, A. M.; Grubb, M.; Hansen, A. G.; Wackerbarth, H.; Welinder, A. C.; Ulstrup, J. Electrochim. Acta 2005, 50, 3143.

(40) Albrecht, T.; Guckian, A.; Ulstrup, J.; Vos, J. G. IEEE Transactions on Nanotechnology 2005, 4, 430.

(41) Albrecht, T.; Guckian, A.; Ulstrup, J.; Vos, J. G. Nano Lett. 2005, 5, 1451.

(42) Alessandrini, A.; Salerno, M.; Frabboni, S.; Facci, P. Appl. Phys. Lett. 2005, 86, 3.

(43) Albrecht, T.; Moth-Poulsen, K.; Christensen, J. B.; Guckian, A.; Bjornholm, T.; Vos, J. G.; Ulstrup, J. Faraday Discuss. 2006, 131, 265.

(44) Albrecht, T.; Guckian, A.; Kuznetsov, A. M.; Vos, J. G.; Ulstrup, J. J. Am. Chem. Soc. 2006, 128, 17132.

(45) Davis, J. J.; Peters, B.; Xi, W. Journal of Physics-Condensed Matter 2008, 20, 374123.

(46) Pobelovt, I. V.; Li, Z. H.; Wandlowski, T. J. Am. Chem. Soc. 2008, 130, 16045.

(47) Rudnev, A. V.; Pobelov, I. V.; Wandlowski, T. J. Electroanal. Chem. 2011, 660, 302.

(48) Chi, Q. J.; Zhang, J. D.; Jensen, P. S.; Christensen, H. E. M.; Ulstrup, J. Faraday Discussions 2006, 131, 181.

(49) Chi, Q. J.; Farver, O.; Ulstrup, J. Proceedings of the National Academy of Sciences of the United States of America 2005, 102, 16203.

(50) Della Pia, E. A.; Chi, Q.; Jones, D. D.; Macdonald, J. E.; Ulstrup, J.; Elliott, M. Nano Lett. 2011, $11,176$.

(51) Hansen, A. G.; Salvatore, P.; Karlsen, K. K.; Nichols, R. J.; Wengel, J.; Ulstrup, J. Phys. Chem. Chem. Phys. 2013, 15, 776.

(52) Salvatore, P.; Zeng, D.; Karlsen, K. K.; Chi, Q.; Wengel, J.; Ulstrup, J. Chemphyschem 2013, 14, 2101. 
(53) Albrecht, T.; Moth-Poulsen, K.; Christensen, J. B.; Hjelm, J.; Bjornholm, T.; Ulstrup, J. J. Am. Chem. Soc. 2006, 128, 6574.

(54) Tran, E.; Duati, M.; Whitesides, G. M.; Rampi, M. A. Faraday Discuss. 2006, 131, 197.

(55) Gittins, D. I.; Bethell, D.; Schiffrin, D. J.; Nichols, R. J. Nature 2000, 408, 67.

(56) He, H. X.; Li, X. L.; Tao, N. J.; Nagahara, L. A.; Amlani, I.; Tsui, R. Phys. Rev. B. 2003, 68, 045302.

(57) He, H. X.; Zhu, J. S.; Tao, N. J.; Nagahara, L. A.; Amlani, I.; Tsui, R. J. Am. Chem. Soc. 2001, 123, 7730.

(58) Diez-Perez, I.; Li, Z. H.; Guo, S. Y.; Madden, C.; Huang, H. L.; Che, Y. K.; Yang, X. M.; Zang, L.; Tao, N. J. ACS Nano 2012, 6, 7044.

(59) Artes, J. M.; Diez-Perez, I.; Gorostiza, P. Nano Lett. 2012, 12, 2679.

(60) Della Pia, E. A.; Chi, Q.; Macdonald, J. E.; Ulstrup, J.; Jones, D. D.; Elliott, M. Nanoscale 2012, $4,7106$.

(61) Fedorov, M. V.; Kornyshev, A. A. Chem. Rev. 2014, 114, 2978.

(62) Gittins, D. I.; Bethell, D.; Nichols, R. J.; Schiffrin, D. J. Adv. Mater. 1999, 11, 737.

(63) Sonogashira, K. J. Organomet. Chem. 2002, 653, 46.

(64) Sonogashira, K.; Tohda, Y.; Hagihara, N. Tetrahedron Lett. 1975, 4467.

(65) Chinchilla, R.; Najera, C. Chem. Rev. 2007, 107, 874.

(66) Barnett, D. S.; Schaus, S. E. Org. Lett. 2011, 13, 4020.

(67) Connelly, N. G.; Geiger, W. E. Chem. Rev. 1996, 96, 877.

(68) Marques-Gonzalez, S.; Yufit, D. S.; Howard, J. A. K.; Martin, S.; Osorio, H. M.; Garcia-Suarez, V. M.; Nichols, R. J.; Higgins, S. J.; Cea, P.; Low, P. J. Dalton Transactions 2013, 42, 338.

(69) Pera, G.; Martin, S.; Ballesteros, L. M.; Hope, A. J.; Low, P. J.; Nichols, R. J.; Cea, P. Chemistrya European Journal 2010, 16, 13398.

(70) Kim, H. J.; Jeon, W. S.; Ko, Y. H.; Kim, K. Proc. Nat. Acad. Sci. U.S.A. 2002, 99, 5007.

(71) Vergeer, F. W.; Kleverlaan, C. J.; Matousek, P.; Towrie, M.; Stufkens, D. J.; Hartl, F. E. Inorg. Chem. 2005, 44, 1319.

(72) Porter, W. W.; Vaid, T. P. J. Org. Chem. 2005, 70, 5028.

(73) Zhang, J. D.; Kuznetsov, A. M.; Medvedev, I. G.; Chi, Q. J.; Albrecht, T.; Jensen, P. S.; Ulstrup, J. Chem. Rev. 2008, 108, 2737.

(74) Artes, J. M.; Lopez-Martinez, M.; Giraudet, A.; Diez-Perez, I.; Sanz, F.; Gorostiza, P. J. Am. Chem. Soc. 2012, 134, 20218.

(75) Millar, D.; Venkataraman, L.; Doerrer, L. H. J. Phys. Chem. C 2007, 111, 17635.

(76) Leblanc, N.; Mercier, N.; Toma, O.; Kassiba, A. H.; Zorina, L.; Auban-Senzier, P.; Pasquier, C. Chem. Commun. 2013, 49, 10272.

(77) Hiraoka, S.; Hirata, K.; Shionoya, M. Angew. Chem. Int. Ed. 2004, 43, 3814.

(78) Leventis, N.; Rawashdeh, A. M. M.; Elder, I. A.; Yang, J. H.; Dass, A.; Sotiriou-Leventis, C. Chem. Mater. 2004, 16, 1493.

(79) Nichols, R. J.; Haiss, W.; Higgins, S. J.; Leary, E.; Martin, S.; Bethell, D. Phys. Chem. Chem. Phys. 2010, 12, 2801.

(80) Krejčík, M.; Daněk, M.; Hartl, F. J. Electroanal. Chem. 1991, 317, 179. 


\section{$\underline{\text { TOC GRAPHIC }}$}

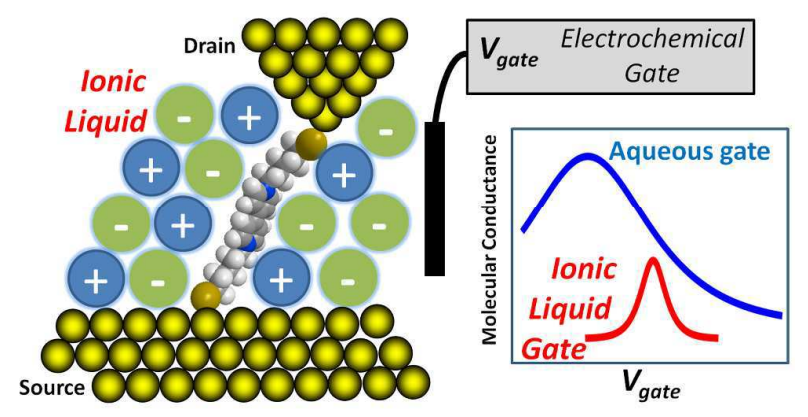

19

20

21

22

23

24

25

26

27

28

29

30

31

32

33

34

35

36

37

38

39

40

41

42

43

44

45

46

47

48

49

50

51

52

53

54

55

56

57

58

59

60 


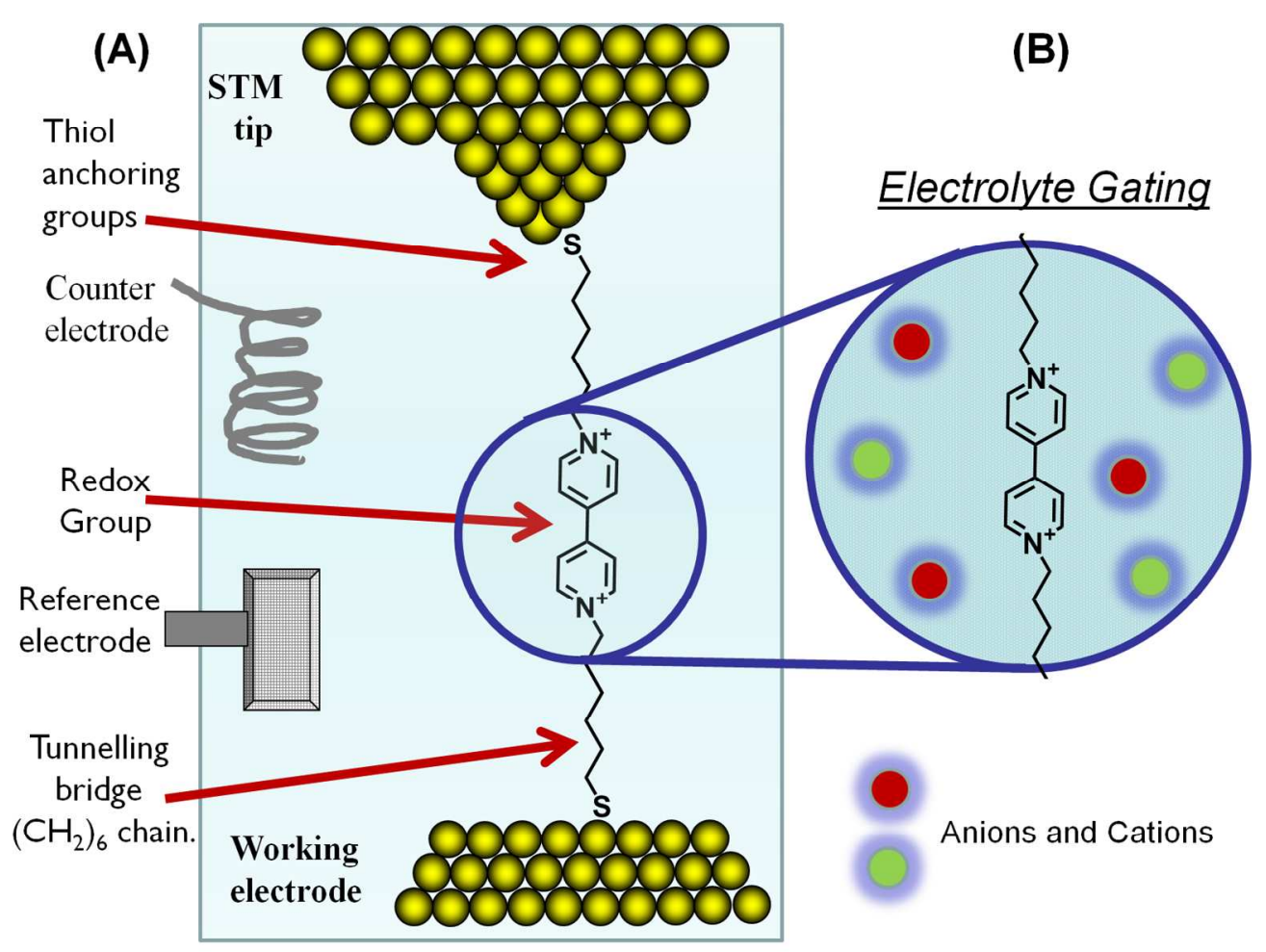

(A) Electrochemical single molecule gating using an electrochemical STM with bipotentiostat control of the electrochemical potential of the substrate and STM tip. The single molecule bridge shown here $\left(\mathbf{1}^{2+}\right.$, see below) is derived from 1, $1^{\prime}$-bis(6-(acetylthio)hexyl)-4,4'-bipyridinium hexafluorophosphate. (B) Illustrates the close proximity of the electrolyte ions which are "gating" the redox group (the electrolyte gating concept). 


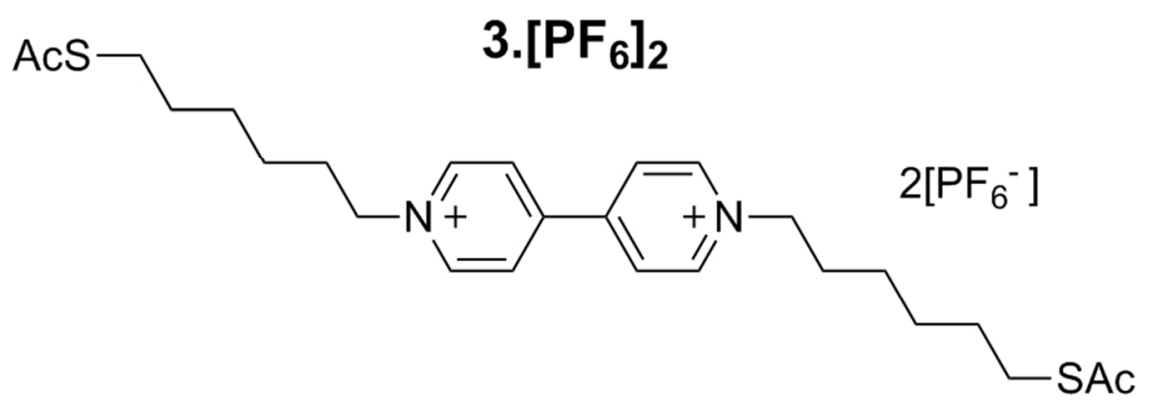

The viologen based molecular wires $\left(\mathbf{1}^{\mathbf{2 +}}\right.$ and $\left.\mathbf{2}^{\mathbf{2 +}}\right)$ used in the STM studies described within. Under the experimental conditions used the counter ions are determined by the electrolytic medium. $\mathbf{3} \cdot\left[\mathrm{PF}_{6}\right]_{2}$ is the acetyl protected precursor of $\mathbf{1}^{2+}$ with $\mathrm{PF}_{6}{ }^{-}$counter-ions. $212 \times 250 \mathrm{~mm}(120 \times 120 \mathrm{DPI})$ 
Cyclic voltammograms recorded for $3 \times 10^{-3} \mathrm{M}$ of the thioacetate protected form of $\mathbf{1}^{\mathbf{2 +}}$ (3.[PF6]2) in BMIMOTf for 11 different scan rates and $\mathrm{Au}(111)$ working electrodes. The redox wave on the left corresponds to the viologen dication/radical cation redox couple, while the redox wave centered at $0 \mathrm{~V}$ arises from ferrocene added to the electrolyte as internal standard. The CVs were recorded at $0.05 \mathrm{~V} / \mathrm{s}, 0.1 \mathrm{~V} / \mathrm{s}$ and then in $0.1 \mathrm{~V}$ intervals to $1 \mathrm{~V} / \mathrm{s}$.

$348 \times 262 \mathrm{~mm}(120 \times 120 \mathrm{DPI})$ 

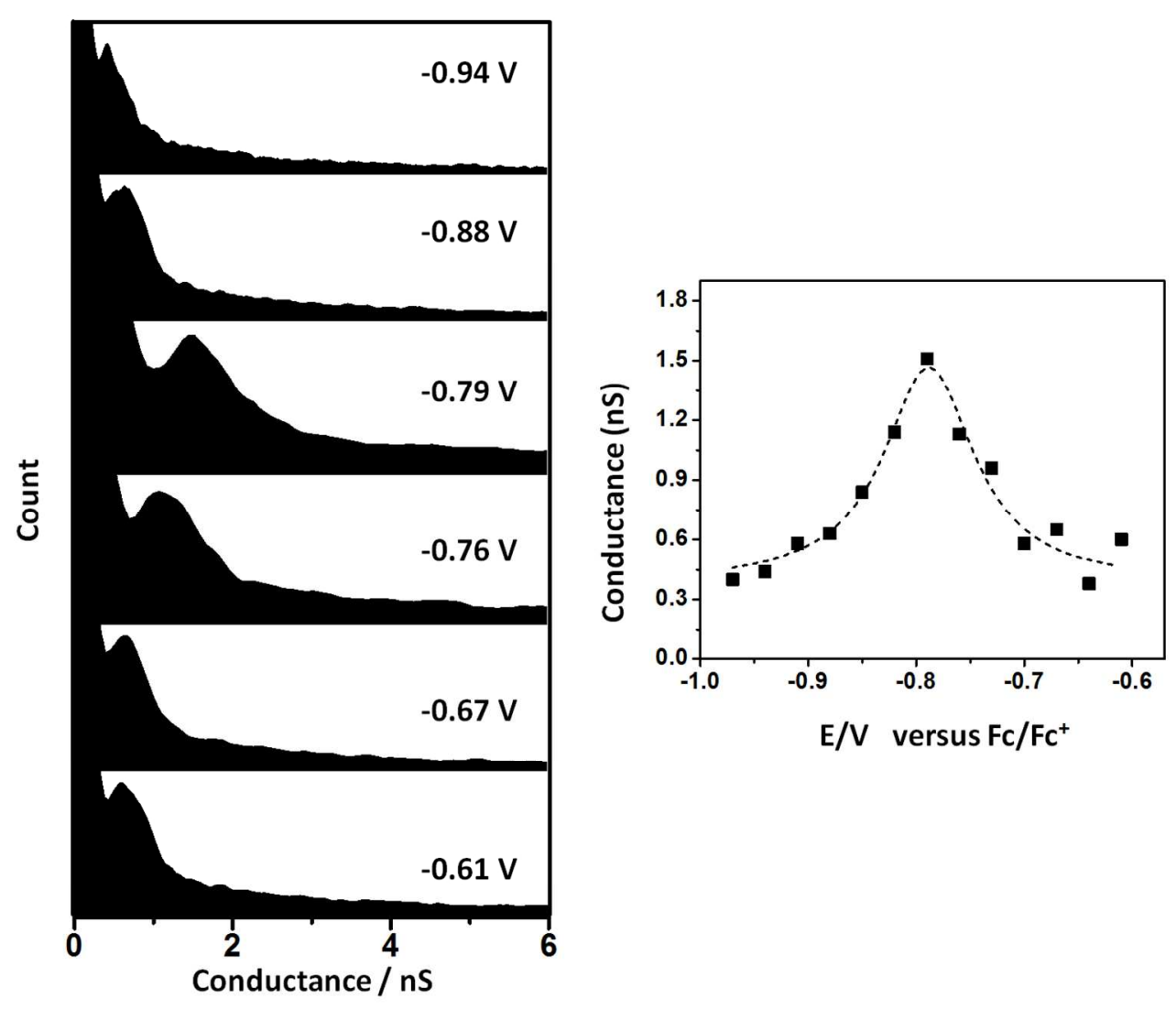

Left: conductance histograms recorded for molecular bridges formed from $\mathbf{1}^{\mathbf{2 +}}$ in ionic liquid electrolyte as a function of the marked electrochemical potential (versus $\mathrm{Fc} / \mathrm{Fc}^{+}$at $0.0 \mathrm{~V}$ ). Right: The single-molecule conductance of $\mathbf{1}^{\mathbf{2 +}}$ versus electrochemical potential. $317 \times 264 \mathrm{~mm}(120 \times 120 \mathrm{DPI})$ 

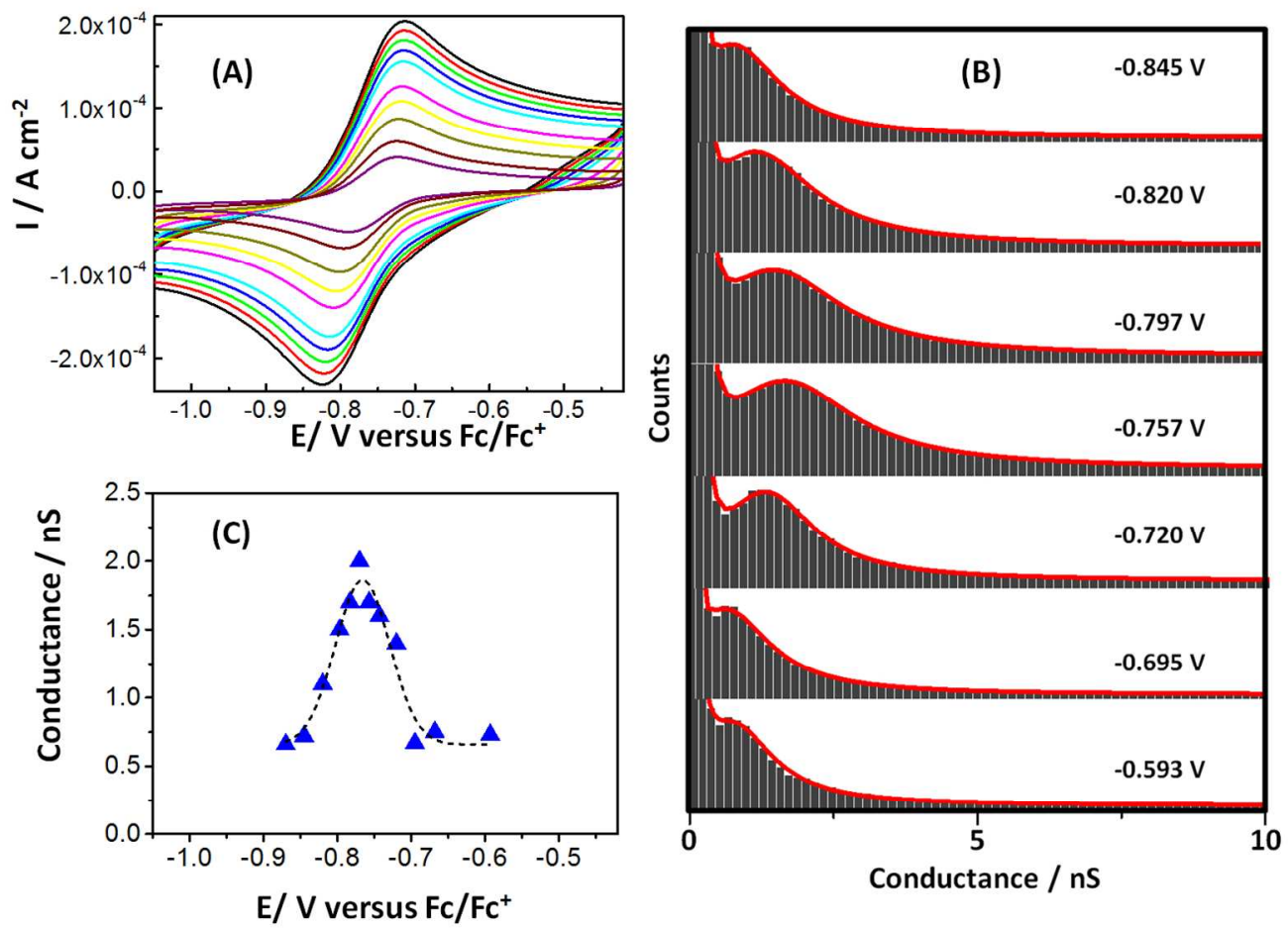

Cyclic voltammograms recorded for the first reduction of $2 \cdot\left[\mathrm{BF}_{4}\right]_{2}$ in BMIM-OTf. The CVs were run at $0.1 \mathrm{~V} \mathrm{~s}^{-}$ ${ }^{1}$ intervals between 0.1 and $1.0 \mathrm{~V} \mathrm{~s}^{-1}$. (B) Conductance histograms recorded for molecular bridges formed from $\mathbf{2}^{\mathbf{2 +}}$ in BMIM-OTf electrolyte as a function of the marked electrochemical potential (versus $\mathrm{Fc} \mathrm{FC}^{+}$at 0.0 V). (C): Single molecule conductance of $\mathbf{2}^{\mathbf{2 +}}$ versus electrode potential in BMIM-OTf. $325 \times 237 \mathrm{~mm}(120 \times 120 \mathrm{DPI})$ 

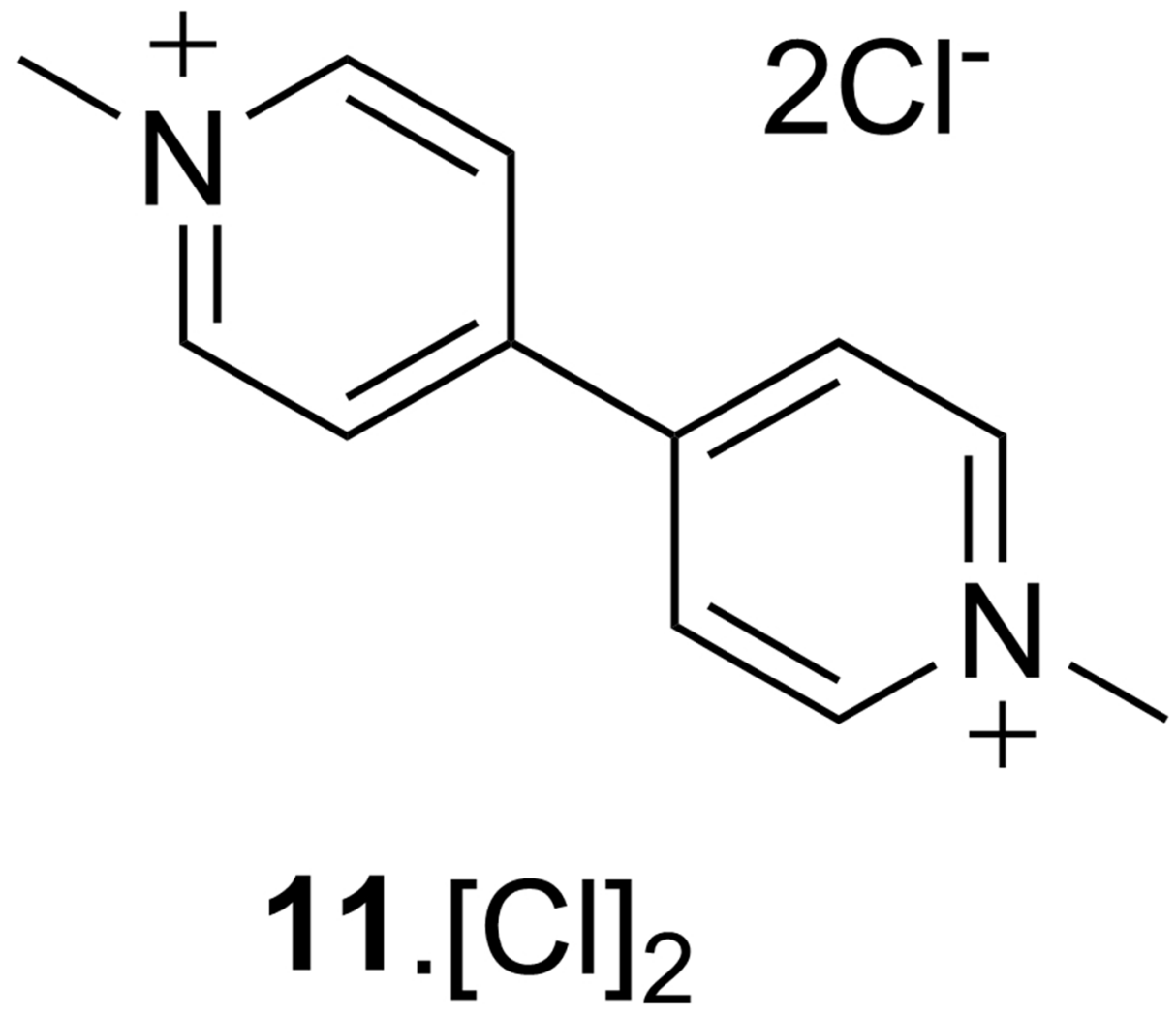

The model methyl viologen dichloride, $\mathbf{1 1} \cdot[\mathrm{Cl}]_{2}$. $202 \times 177 \mathrm{~mm}$ (120 x 120 DPI) 

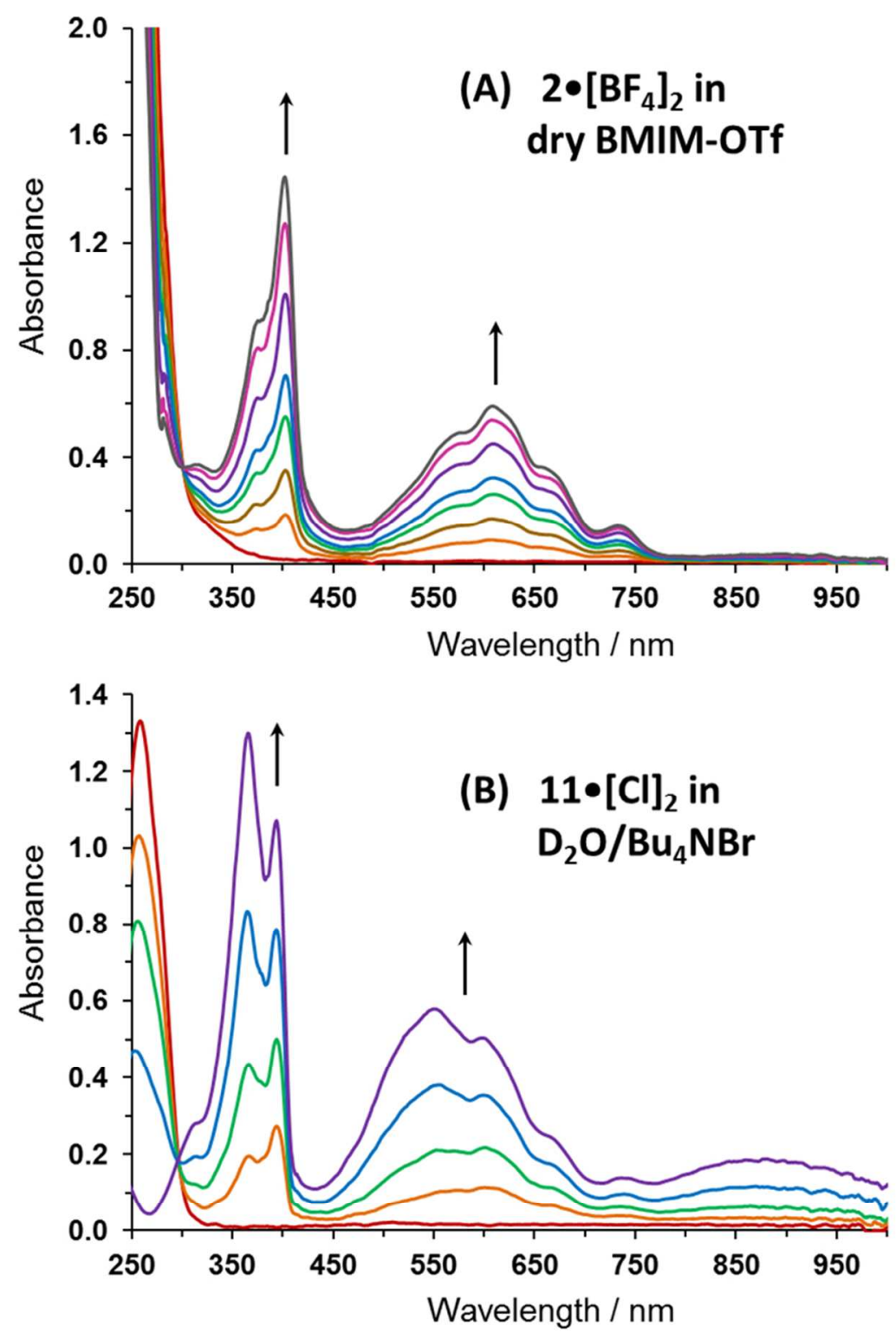

Reversible UV-Vis spectral changes accompanying the reduction of $(A)$ ca $2 \mathrm{mM} \mathbf{2} \cdot[\mathrm{BF}]_{2}$ in $\mathrm{BMIM}-\mathrm{OTf}$ to its stable radical cation within an optically transparent thin layer electrochemical (OTTLE) cell (I $0.2 \mathrm{~mm}$ ) at $\mathrm{T}$ $=293 \mathrm{~K}$. (B) Reversible UV-Vis spectral changes accompanying the reduction of $2 \mathrm{mM} \mathbf{1 1} \cdot[\mathrm{Cl}]_{2}$ in $\mathrm{D}_{2} \mathrm{O} / \mathrm{Bu}_{4} \mathrm{NBr}$ to a radical cation and its subsequent dimerization within an OTTLE cell at $\mathrm{T}=293 \mathrm{~K}$. As the doublet around $\sim 380 \mathrm{~nm}$ grows there is an inversion in intensities. This and the growing absorption at $\sim 870$ $\mathrm{nm}$ are ascribed to dimerization of the radical cation in the aqueous electrolyte. These features are not observed in BMIM-OTf, see Figure S17. $172 \times 253 \mathrm{~mm}(120 \times 120 \mathrm{DPI})$ 


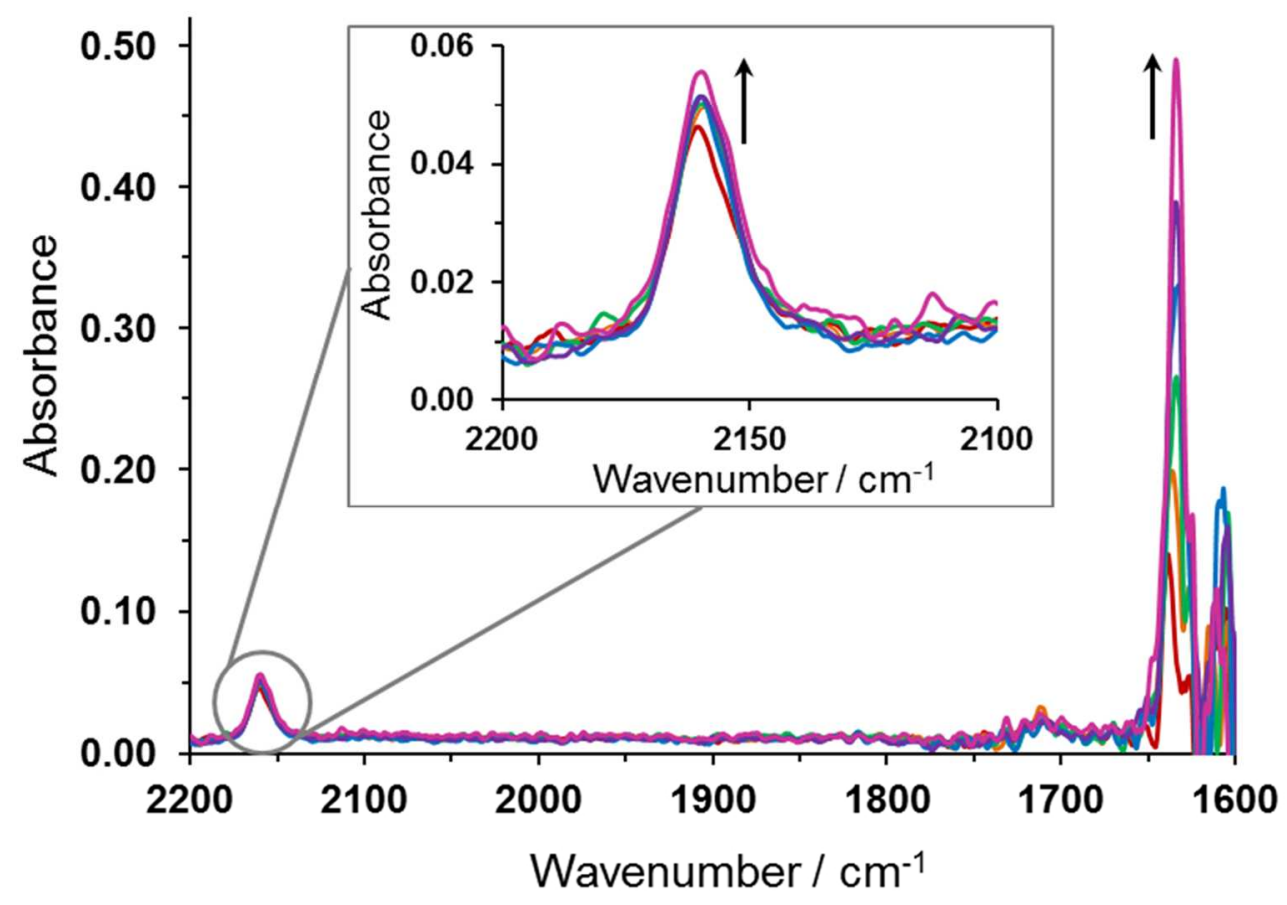

Reversible IR spectral changes accompanying the reduction of $10 \mathrm{mM} \mathbf{2} \cdot\left[\mathrm{BF}_{4}\right]_{2}$ in BMIM-OTf to its stable radical cation within an OTTLE cell at $T=293 \mathrm{~K}$. $299 \times 215 \mathrm{~mm}(120 \times 120$ DPI $)$ 


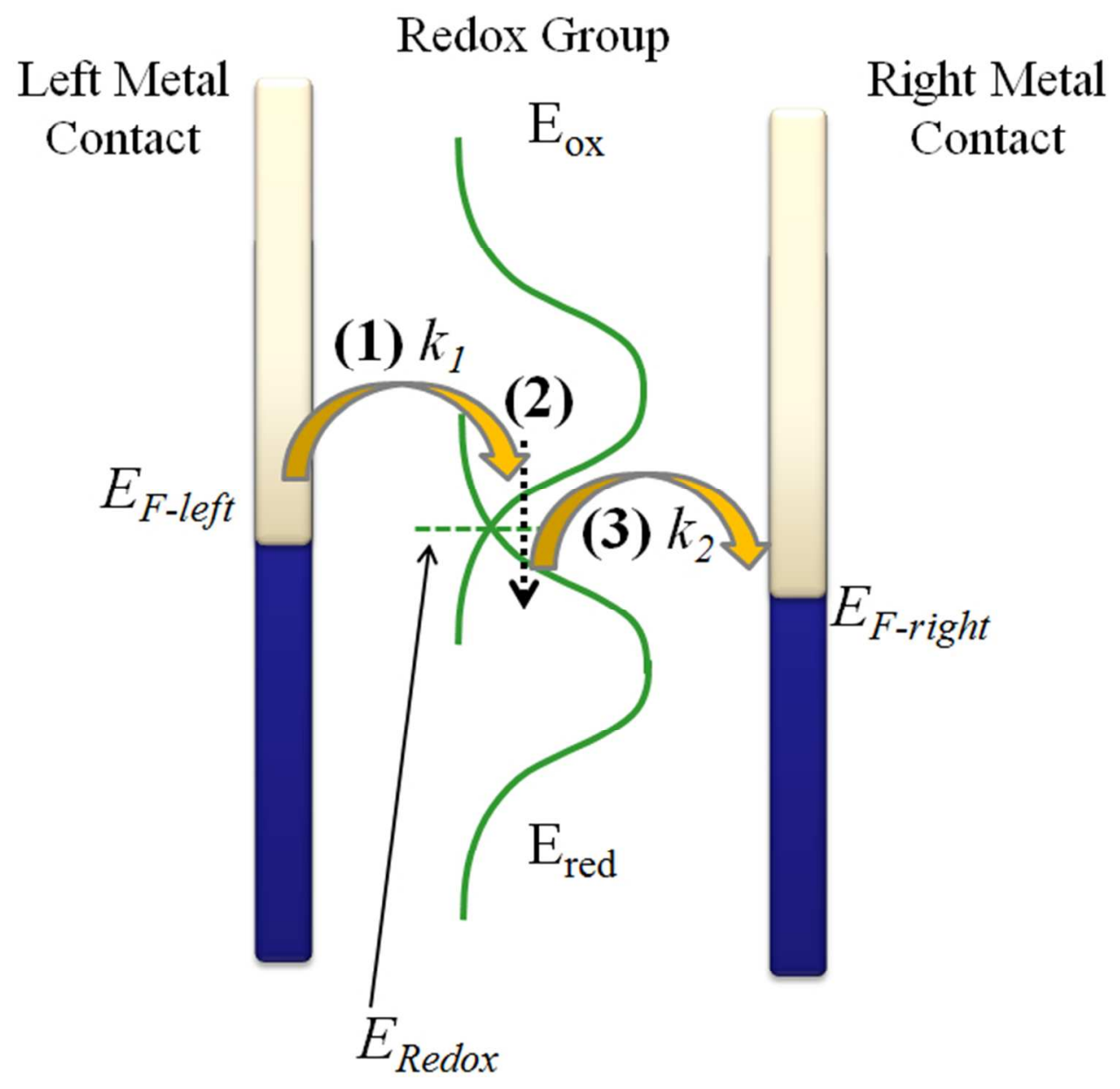

This illustrates the 2-step adiabatic Kuznetsov- Ulstrup model used here show the two gold electrodes ("left" and "right" and the redox states of the molecular bridge in between). This proceeds with electron transfer from the left metal contact onto the redox group following pre-organization at and around the redox center The rate of electron transfer is represented by the electrochemical rate constant $k_{1}$ (step 1 ). The now reduced redox group and surrounding environment partially relax (step 2 ). This is followed by electron transfer from the redox group (re-oxidation) onto the right contact with the electrochemical rate constant $k_{2}$ (step 3), resulting in a cascade of electron transfer between the electrodes through the partially relaxed state of the redox bridge. $142 \times 135 \mathrm{~mm}(120 \times 120$ DPI $)$ 

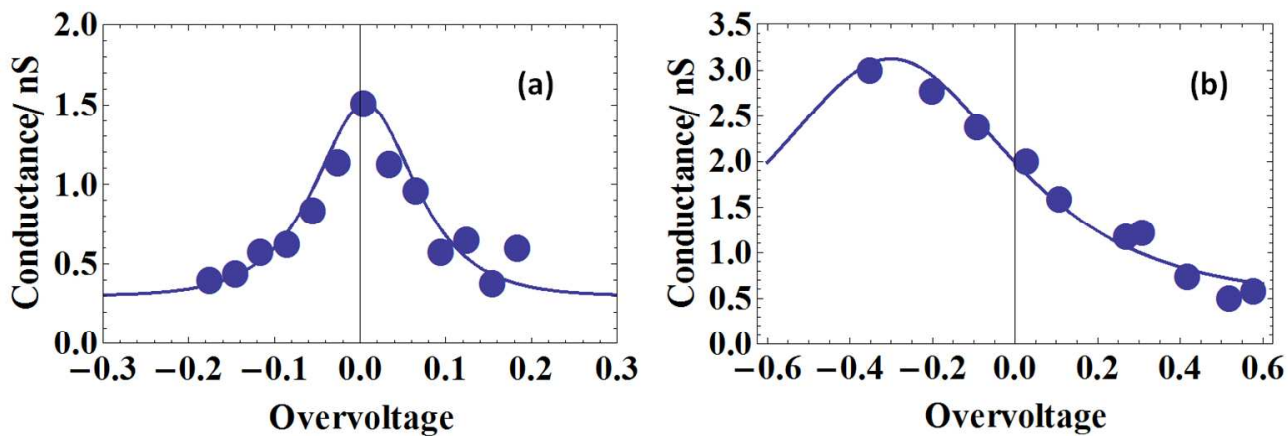

Single molecule conductance data (blue circles) and fitting with equation 1 (solid blue lines), for $\mathbf{1}^{\mathbf{2 +}}$ in BMIM-OTf (a) and aqueous electrolytes (b). Experimental data in (b) was recorded in $0.1 \mathrm{M}$ phosphate buffer solution and is taken from refs. ${ }^{10,12}$. $342 \times 114 \mathrm{~mm}(120 \times 120 \mathrm{DPI})$ 